\title{
Estructura y Maquetación con Diseño Adaptativo para Sitios Web sobre Autismo
}

\section{Structure and Mock-Up with Responsive Design for Websites about Autism}

\author{
Victoria Salcedo \\ Escuela Superior Politécnica del \\ Litoral \\ Guayaquil, Ecuador \\ vsalcedo@espol.edu.ec \\ Orcid: 0000-0001-8519-768X
}

\author{
Nayeth Solórzano Alcívar \\ Escuela Superior Politécnica del \\ Litoral \\ Guayaquil, Ecuador \\ nsolorza@espol.edu.ec \\ Orcid: 0000-0002-5642-334X
}

\author{
Lourdes Pilay \\ Escuela Superior Politécnica del \\ Litoral \\ Guayaquil, Ecuador \\ mdpilay@espol.edu.ec \\ Orcid: 0000-0002-9496-1149
}

\begin{abstract}
Resumen - En la actualidad, el internet es una de las principales fuentes de información que acceden los padres de niños y niñas con Trastorno del Espectro Autista (TEA), o que sospechan que sus hijos lo puedan tener. Esta situación hace relevante la existencia de sitios web que ofrecen información a los padres y brindan ayuda en el proceso de acompañamiento de su familiar con TEA. En este artículo se analiza una propuesta de diseño de un sitio web para Autismo Ecuador, una organización que trabaja en beneficio de las personas con TEA y sus familias. Esta organización es una de las pocas en el país que cuenta con una página web, sin embargo, no está actualizada. La propuesta, presenta un estudio del diseño gráfico y su aplicación en el desarrollo de un sitio web estructurado y adaptativo para poblaciones involucradas con TEA, con el fin de otorgar mayor visibilidad e imagen comunicacional a Autismo Ecuador. La investigación ofrece un enfoque pragmático a través del diseño, se aplican herramientas cualitativas para el análisis y recolección de datos, con estrategias de Diseño Centrado en el Usuario. Inicia con técnicas como Design Thinking, etnografía y antropología visual, entrevistas y grupos focales, para recopilación de la información. Los resultados del análisis se toman como base para la maquetación y obtención de un diseño bien estructurado y pensado en el usuario. Un diseño previo a su implementación muestra la funcionalidad de un sitio web visualmente atractivo, con un elevado nivel comunicacional y aspectos adaptativos para su uso hasta en dispositivos móviles.
\end{abstract}

Palabras Clave: Diseño Web, Diseño Responsivo, Trastorno del Espectro Autista, TEA, Usabilidad.
Abstract - Nowadays, the Internet is one of the primary sources of information for parents of children diagnosed with the Autism Spectrum Disorder (ASD), or those who suspect that their children have it. This situation makes relevant the existence of websites that offer information to parents and provide help in the process of accompanying their family member with ASD. This article analyzes a proposal for the design of a website for Autism Ecuador, an organization that works for the benefit of people with ASD and their families. This organization is one of the few in the country with a website; however, it is not updated. This proposal presents a study of the graphic design and its application to develop a structured and adaptative website for populations involved with ASD, seeking to grant greater visibility and communicational image to Autism Ecuador. This research offers a pragmatic approach through design; qualitative tools are applied for data analysis and collection, with User Centered Design strategies. It begins with Design Thinking techniques, ethnography, visual anthropology, interviews, and focus groups, for data collection. The analysis results are taken as a basis for the layout and obtaining a well-structured and user-oriented design. A design before its implementation shows the functionality of a visually attractive website, with a high communicational level and adaptative aspects to be used even in mobile devices.

Keywords: Web Design, Responsive Design, Autismo Ecuador, Autism Spectrum Disorder.

Sumario: I Introducción, II Metodología, III Procesos de Diseño y Desarrollo, IV Presentación de Resultados y Discusión, V Conclusiones y Trabajos Futuros.

Como citar: Salcedo, Victoria., Solórzano, Nayeth., \& Pilay, Lourdes. (2020). Estructura y Maquetación con Diseño Adaptativo para Sitios Web sobre Autismo. Revista Tecnológica - Espol, 32(2). Recuperado a partir de http://www.rte.espol.edu.ec/index.php/tecnologica/article/view/775 


\section{INTRODUCCIÓN}

El internet es una de las principales fuentes de información para los padres que reciben el diagnóstico de sus hijos con Trastorno del Espectro Autista (TEA) o que sospechan que lo puedan tener, por tanto, se vuelve relevante para estas familias la existencia de sitios web que les permitan encontrar información confiable y que les brinde ayuda en el proceso de acompañamiento de su familiar con TEA. En este contexto, es indispensable que el contenido de los sitios web relacionados con TEA sea de calidad y confiable ya que de ello depende, en gran medida, las acciones a tomar por parte de quienes están relacionados o tienen responsabilidades de seguimiento y control de las personas diagnosticadas [1].

Hoy en día es común escuchar hablar del término "autismo", sin embargo, el desconocimiento aún persiste. López-Chávez and Larrea-Castelo [2], afirman que este grupo social sigue a la espera de reconocimiento y atención en todos los ámbitos; inclúyase el de la salud, social, educativo e, inclusive, el económico. Su investigación pone en evidencia las dificultades que atraviesan las familias en Ecuador para acceder a un proceso de evaluación y diagnóstico.

Existen varias asociaciones en Ecuador que tienen como propósito informar y apoyar de alguna manera a las personas con TEA y a sus familias. Aunque muchas de las organizaciones en el país buscan brindar ayuda y servicios a este grupo social, muy pocas cuentan con un sitio web. Al realizar una búsqueda en internet acerca de sitios web sobre autismo en Ecuador, se encontraron pocos sitios. Entre ellos, se puede mencionar a la Fundación Entra a mi Mundo y Autismo Ecuador. Estas fundaciones, en sus páginas web, presentan el uso de plantillas preestablecidas y muestran una deficiencia en el proceso de diseño para su interfaz, respectivamente. Otras organizaciones como la Federación Ecuatoriana del Espectro Autista (FEDEA) y Fundación Asperger Ecuador redirigen a la red social Facebook, presentando sus contenidos con el uso de fan pages.

En el caso de Autismo Ecuador, organización sin fines de lucro, en el año 2013 crea un sitio web que busca sensibilizar a la comunidad. Para ello, difunde contenidos con información relevante acerca de esta condición. Sin embargo, el diseño de su sitio web se ha mantenido sin modificaciones desde su creación, por lo que no muestra contenido actualizado ni está sujeto a las tendencias que se manejan actualmente para el desarrollo de interfaces para sitios web. Por otro lado, Autismo Ecuador no se enlaza con otras redes sociales, lo que beneficiaría a la visibilidad del sitio, tampoco cuenta con un diseño responsivo. Quiere decir, que no se adapta a dispositivos móviles lo que, hoy en día, es muy importante para cualquier organización que desee difundir ampliamente sus contenidos.

La necesidad de sitios web actualizados y con diseño responsivo se revisa a través de este caso, pues a pesar de que la página de Autismo Ecuador aparentemente se encuentra posicionada entre los primeros lugares en su género en visualización de búsqueda local con 9349 visitas entre el año 2019 a junio del 2020, se tiene como resultado que el sitio es visitado, pero abandonado casi inmediatamente. Esta información se puede constatar por medio de las estadísticas que arroja el servidor y que indican que el $81,3 \%$ de los usuarios abandona el sitio en menos de 30 segundos de haber ingresado.

En su página web, Autismo Ecuador declara que su misión es convertirse en la agrupación social más importante del país con el propósito de velar y mejorar las condiciones de vida de las personas con autismo y su familia. De esta forma se busca apoyar el logro de su objetivo. Se toma este caso para constatar que el efecto de maquetación de un sitio estructurado, intuitivo y con diseño adaptativo, sirve como estrategia fundamental para obtener mayor visibilidad y tiempo de visita en una página web.

El presente artículo guía el proceso de un nuevo diseño para el sitio web de Autismo Ecuador cuyo fin es lograr un mayor posicionamiento, ampliando su visibilidad para continuar con su objetivo de difusión y sensibilización sobre la condición del TEA. Al mismo tiempo, brinda a los padres y familiares de personas con TEA información y orientación oportuna.

\section{A. Estado del arte}

Se ha demostrado que los padres tienen como principal fuente de información el internet, sin embargo, es importante recalcar que revisar información de varias fuentes puede resultar confuso y poco confiable [3]. Por lo que se considera que el sitio actualizado, bien estructurado e intuitivo, con contenidos apropiados y según las necesidades de los padres y comunidad en general relacionados con niños, jóvenes y adultos diagnosticados con TEA, puede convertirse en una herramienta de apoyo informativo muy relevante para este grupo social. Para ello, previo al desarrollo del sitio web, se debe considerar los siguientes aspectos: Identificar el público objetivo para el cual estará dirigido el proyecto, analizar los temas relevantes que se investigarán según el contexto para su elaboración, determinar los diseños y elementos visuales a desarrollar, utilizar según un análisis preliminar y organizar la información pertinente a presentar en el sitio web.

1) El Trastorno del Espectro Autista y su difusión en Ecuador: La American Psychiatric Association (APA) en el 2013, por medio del Manual de Diagnóstico y Estadístico de los Trastornos Mentales Quinta Edición (DSM-5) agrupa en un solo concepto los criterios de los trastornos generalizados del desarrollo: Trastorno del Espectro Autista, y lo define como "un déficit persistente en la comunicación social y la interacción social en distintos contextos, no explicable por un retraso general en el desarrollo" [4] (p. 684).

Autores como Salvadó, Palau, Clofent, Montero and Hernández [5] y McPartland, Reichow and Volkmar [6] coinciden en que, si bien el TEA se manifiesta de diversas maneras y con conductas diferentes en cada individuo, esta condición presenta algunas características precisas que lo identifican. Entre ellas tenemos: la dificultad para comunicarse y socializar, dificultad para desarrollar el lenguaje $\mathrm{y}$, además, los intereses focalizados y comportamiento repetitivo, tal como se especifica en la última edición del DSM-5. 
Cualquier indicio sobre las características mencionadas puede ser observado durante los primeros tres años de vida, lo que da grandes posibilidades para tomar acción y mejorar la calidad de vida de una persona con TEA[7]. Esta identificación se logra a través de intervenciones idóneas y adaptadas a las necesidades de cada sujeto. No obstante, como dice la Asociación Psiquiátrica Americana (American Psychiatric Association) [8], el TEA “puede no ser detectado hasta más tarde debido a las mínimas demandas sociales y al apoyo en los primeros años de los padres" [7] (p. 244).

Salvadó, Palau, Clofent, Montero and Hernández [5], destacan tres grandes grupos en los que se dividen estos tratamientos: Las prácticas basadas en la evidencia, las prácticas basadas en la intervención y las terapias bajo los modelos globales de tratamiento. Sin embargo, Prizant, Wetherby and Rydell [9], sugieren la integración de las intervenciones en un solo grupo que contengan dos extremos: uno de tratamientos conductuales rigurosos, y en el otro los tratamientos que se enfocan en el desarrollo social, ya que se considera que de esta manera se obtienen mejores resultados.

En el 2007, Naciones Unidas declaró el 2 de abril como el Día Mundial de la Concienciación sobre el Autismo [10]. Según los padres y familiares de personas con TEA, durante los últimos años se ha adoptado en el país, con el apoyo de algunos organismos públicos, la iniciativa de "pintar" o "encender" este día de azul, que es el color que representa al TEA a nivel mundial, con la finalidad de dar notoriedad en la sociedad sobre esta condición. Por medio de concentraciones de algunas organizaciones del país y el encendido de luces azules en edificios o monumentos de algunas ciudades se busca, de alguna manera, recordarle a la sociedad que existen personas con esta discapacidad.

Entre estas organizaciones se encuentran FEDEA, Fundación Entra a Mi Mundo, Fundación Asperger Ecuador, Centro Psicoeducativo Integral Isaac, Asociación de Padres APADA del Ecuador, Fundación Comunicar y Autismo Manabí. Tomando en cuenta la referencia anterior, si hacemos un recorrido en un buscador de internet, la gran mayoría de organizaciones no cuenta con un sitio web; en su lugar, tienen como medio principal de difusión la red social Facebook por medio de fan pages.

2) Sitios web relacionados con TEA: Coincidiendo con varios autores, [Reichow, Halpern, Steinhoff, Letsinger, Naples and Volkmar [3]], afirman que el internet es el medio por el cual la mayoría de las personas obtienen información y que entre los principales motores de búsqueda se encuentra Google. Así mismo, los padres o familiares de personas con TEA también tienen como principal fuente de información el internet para realizar búsquedas sobre este tema [11].

A pesar de esto, estudios como el realizado por Eysenbach and Köhler [12] demostraron que, al ejecutar búsquedas relacionadas con temas de salud en internet, accedían a la información rápidamente, pero solía no ser de una calidad confiable. En relación con lo anterior, Scullard, Peacock and Davies [13], manifiestan en su estudio que, al hacer una búsqueda en Google sobre autismo, se produjeron muchos resultados, aunque carentes de exactitud.
Reichow, Halpern, Steinhoff, Letsinger, Naples and Volkmar [3], hicieron un experimento rápido para demostrar el incremento del interés por los temas relacionados con el autismo en el año 2010. Referente a este experimento, al realizar una prueba en Google utilizando como palabra clave "autismo", en julio de 2020, el motor de búsqueda arrojó un resultado de 22,600,000 enlaces relacionados con el tema, lo que confirma que al pasar de los años sigue aumentando el interés por el TEA.

Entonces, si bien es cierto que se muestra un incremento en el interés por los temas relacionados con el autismo, no hay mucha información respecto a los sitios web sobre el TEA, como aseguran Reichow, Halpern, Steinhoff, Letsinger, Naples and Volkmar [3]. Su afirmación se basa en estudios realizados por Chowdhury, Drummond, Fleming and Neitfeld [11], entre los cuales destaca que se hizo una revisión de 145 páginas web, de las cuales un $80 \%$ mostraban contenido que no era verificable. Con relación a esto, Bernstam, Shelton, Walji and Meric-Bernstam [14], afirman que no hay una guía adecuada para dar con sitios web que contengan temas sobre TEA de buena calidad.

Dado que es difícil acceder a información relacionada con autismo por los medios tradicionales y que es el internet la mayor fuente de contenido, en el estudio realizado por Chowdhury, Drummond, Fleming and Neitfeld [11], se reunieron sitios web que podrían resultar de utilidad para padres de infantes con TEA, sugiriendo que la calidad de los mismos pueda ser sometida a una evaluación, dado que "coloca a las familias en riesgo de sacar conclusiones sospechosas con respecto a las opciones de tratamiento" (p. 158).

3) Diseño y desarrollo de sitios web: Pedraza-Jiménez, Blanco, Codina and Cavaller [15], sugieren que para el desarrollo o modificación de cualquier sitio web, se debe detallar las características que va a tener en el documento de Especificación de Requerimientos (ER). Esto garantiza que se cumpla el proceso de implementación según lo establecido previamente. También manifiestan que es necesario tomar en cuenta los aspectos funcionales, es decir, los objetivos del sitio web, su público objetivo y las tareas que se van a realizar dentro del sitio. Además, hay que prestar importante atención a los aspectos técnicos, ya que son los que pueden afectar directamente al diseño.

Otro aspecto a tomar en cuenta, como afirma Veloz [16], es que los sitios web deben adaptarse a diversos medios, dado el continuo uso de los teléfonos inteligentes, tabletas e incluso televisores para visualizarlos. "La navegación, utilizando un tipo u otro de dispositivo, cambia de forma radical la experiencia del usuario y por lo tanto los sitios web deben adaptarse a todos estos formatos" (p. 60).

De esta forma surge el término "Responsive Web Design" en el año 2008. Su autor, Ethan Marcotte, formó parte del equipo encargado del rediseño de sitio web de The Boston Globe bajo el término "web para todos", siendo uno de los primeros en adaptarse a estos cambios, lo que permitió el acceso al sitio desde varios dispositivos [16]. Para los diseños responsivos en sitios web para clientes corporativos, Harrell [17] sugiere que se "muestre el mismo contenido a los usuarios, independientemente del dispositivo que estén usando. La única diferencia entre 
pantallas y plataformas es que se tiene que diseñar para varios tamaños de pantalla" (p. 77).

De la mano con el diseño responsivo está la usabilidad, que se mide en factores como eficacia, eficiencia y satisfacción. Como sostiene Krug [18], en el diseño todo tiene que ver con factores que determinen compensaciones, debido a que siempre existen limitaciones. Estos son factores muy importantes a considerar, ya que pueden repercutir directamente en la experiencia del usuario dentro de un sitio web.

Con respecto al acceso a la web, Egri y Bayrak [19] afirman que un usuario generalmente utiliza primero ciertos motores de búsqueda para dirigirse a un sitio web, incluso, sabiendo la dirección de este; siendo Google el más popular. Esta es una de las razones por lo que en la actualidad técnicas como SEO (Search Engine Optimization) son tomadas en consideración como parte del proceso de desarrollo de un sitio web para contribuir a su visibilidad, ya que permiten ubicarlo, mediante su correcta configuración, entre los primeros lugares de búsqueda.

En general, se determinan aspectos relacionados con la necesidad de sitios web bien informados sobre áreas específicas de interés de sus usuarios. Las necesidades de actualizar y utilizar diseño responsivo se revisan a través del caso de rediseño propuesto para la página de Autismo Ecuador la cual, a pesar de ubicarse como posicionada entre los primeros lugares de visualización en su género a nivel local, su tiempo de permanecía por visita de parte de los usuarios es mínimo.

\section{METODOLOGÍA}

Partiendo del conocimiento del tema, el proyecto se definió con parámetros de investigación de nivel exploratorio. Se basó en paradigmas interpretivistas utilizando un método cualitativo como estrategias relacionadas con este enfoque desde el punto de vista del investigador [20]. Esto permitió delimitar la problemática según los antecedentes, la justificación del problema planteado y la definición del objetivo del proyecto, buscando resultados útiles y bien justificados respecto al diseño del nuevo sitio web, relevantes y representativos para el público objetivo.

Por medio de la revisión de la literatura y el análisis de otros sitios web bajo una investigación exploratoria $\mathrm{y}$ descriptiva sobre el tema de estudio, y llevando a cabo entrevistas a padres y expertos en el tema, se analizó la información recolectada aplicando métodos cualitativos.

Como resultado se desarrolló un cuestionario semiestructurado que sirvió como guía para las entrevistas relacionadas al caso sobre "cómo esperan los usuarios ver el sitio web" (ver Anexo A). Posteriormente, se realizaron procesos interpretativos de codificación abierta organizando los datos por códigos axiales, categorías, hasta llegar a temas de interés, logrando realizar un diseño estructurado de las necesidades e intereses planteados por los entrevistados con respecto a los actores involucrados en este caso.

Dada la naturaleza aplicativa de este proyecto, se elaboró un diseño estructural para la investigación del nuevo diseño del sitio web para Autismo Ecuador, siguiendo estrategias sugeridas por Hassan and Martín [21] sobre procedimientos para el diseño de sitios accesibles.

Este nuevo sitio tuvo como punto de partida estrategias de análisis cualitativo que definieron los procesos metodológicos a seguir y las herramientas que fueron de utilidad para identificar los requerimientos funcionales en cuanto al público objetivo y las tareas que este realizará dentro del sitio. Considerando que todo proyecto de diseño pasa por tres etapas principales: Inspiración, ideación e implementación, se aplicaron métodos etnográficos $\mathrm{y}$ antropológicos, Design Thinking y estrategias de grupos focales y entrevistas para recolección y análisis de datos buscando empatizar con el usuario e identificando sus verdaderas necesidades referentes al sitio web (ver Fig. 1)

Bajo este concepto se definieron esquemas etnográficos y antropológicos que se deben tomar en consideración para desarrollar las características del sitio web. También, se aplicaron estrategias con Design Thinking considerando en el proceso los insights (revelaciones) de los autores o partes interesadas, basados en la recolección de datos primarios como parte del proceso de investigación aplicado al diseño que corresponde para el desarrollo de la propuesta. Inicia con el diseño de un prototipado hasta lograr el producto final acorde a las necesidades de los usuarios.

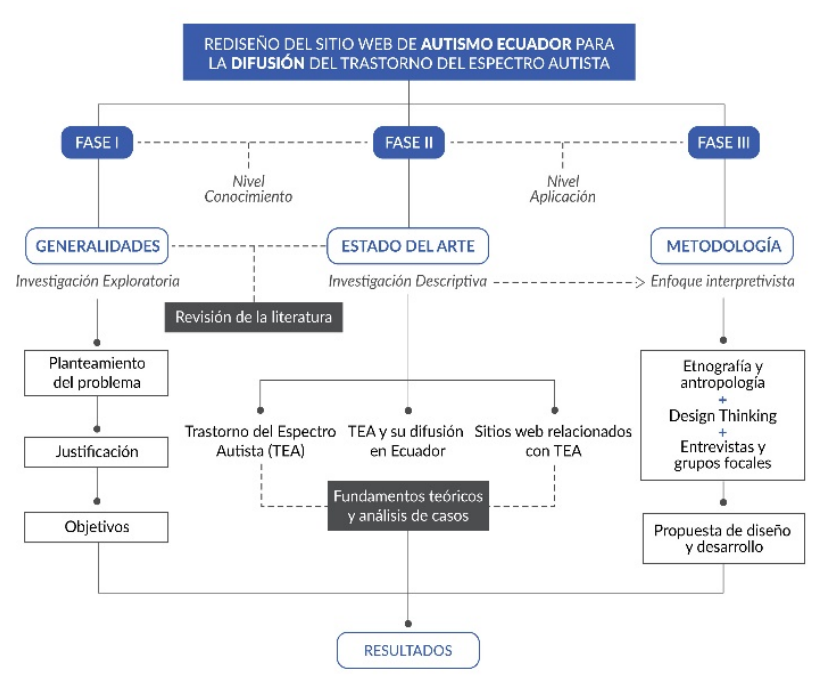

Fig. 1. Diseño de la metodología de investigación para la generación del nuevo sitio web de Autismo Ecuador

\section{PROCESOS DE DISEÑO Y DESARROLLO}

Para el proceso de diseño y desarrollo de un sitio web de calidad sobre autismo, se deben considerar aspectos relacionados con el Diseño Centrado en el Usuario (DCU), dado que esto permite la accesibilidad a un mayor rango de usuarios [21].

\section{A. Design Thinking}

La metodología escogida para determinar las necesidades del usuario fue Design Thinking, definida como "una disciplina que usa la sensibilidad y los métodos del diseñador para hacer coincidir las necesidades de las personas con lo que es tecnológicamente factible" [22] (p. 4). Para la recolección y análisis de la información, se utilizó herramientas con un enfoque interpretivista y estrategias de métodos cualitativos. 


\section{B. Etnografía y antropología visual}

Bajo un esquema observacional, se identificaron características que definen a los miembros de la comunidad TEA. Se utilizó la combinación de las herramientas moodboard y coolboard, lo que permitió establecer coincidencias en el estilo de vida de las familias de personas diagnosticadas con TEA, como podemos ver en la Fig. 2 se determinó que el público objetivo abarca un rango amplio de tipologías que coinciden en varios aspectos que giran en torno al diagnóstico de su familiar. Además, las personas diagnosticadas con TEA también forman parte de este grupo objetivo.

Así mismo, se aplicaron estas herramientas para el proceso de observación y análisis de las tendencias en cuanto a criterios de diseño y estructura utilizados en los sitios web existentes relacionados con TEA en varios países del mundo, como vemos en la Fig. 3.

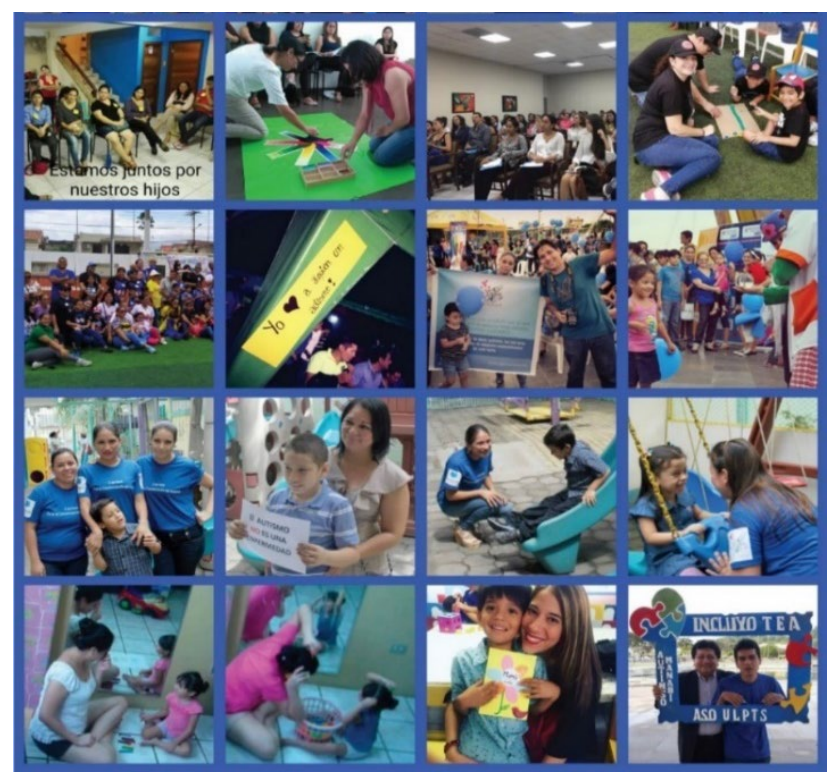

Fig. 2. Familias de personas con Trastorno del Espectro Autista

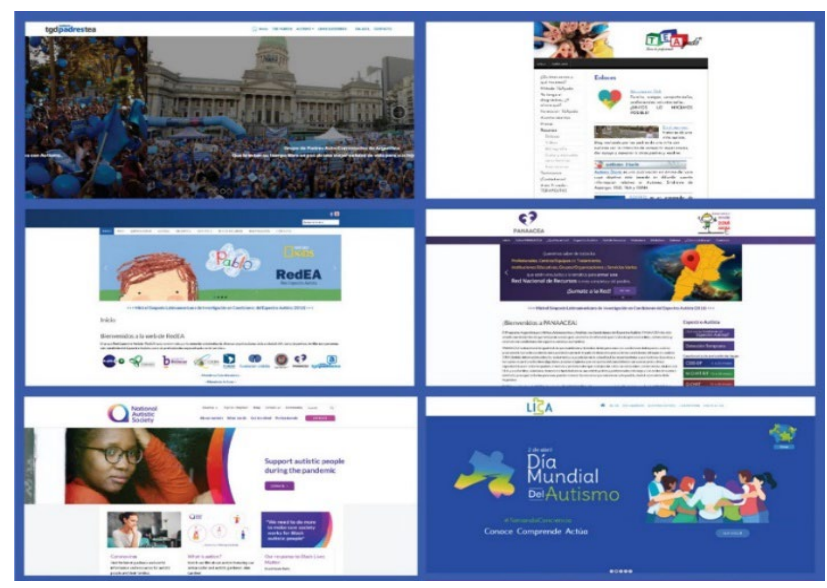

Fig. 3 Tendencias y diseño de sitios web relacionados con TEA

\section{Entrevistas y herramienta Personas}

Utilizando un modelo semiestructurado, se realizaron entrevistas a padres de niños, niñas y jóvenes con TEA con diferentes niveles de funcionamiento. Estas permitieron determinar el contexto y las dificultades que enfrenta la mayoría de los padres en cada etapa del diagnóstico de sus hijos o hijas. Además, se confirmó que la principal fuente de información para un padre o familiar que sospecha o que ya ha recibido el diagnóstico es el internet; así mismo, que es por este medio que los involucrados buscan recursos que les permitan ayudar a sus familiares con autismo.

Adicional a lo anterior, los padres de familia coincidieron en que sería importante contar con un sitio web que les brinde herramientas y les permita compartir experiencias con otros padres o familiares de personas con autismo. Al mismo tiempo que es de gran ayuda para sobrellevar de mejor manera las diferentes etapas que se atraviesan en el acompañamiento de una persona con TEA.

Con base en las entrevistas, se desarrolló un perfil ficticio para la creación de un protagonista para la herramienta Personas (ver Fig. 4), que representa a todo un grupo objetivo. Este proceso permitió explorar a este público, lo que ayudó a empatizar e identificar más claramente cuáles son los aspectos en común que comparten los potenciales usuarios del sitio.

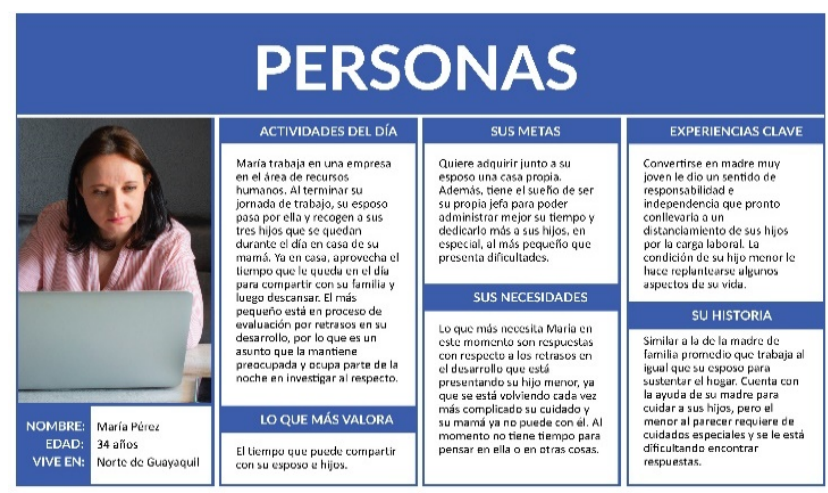

Fig. 4. Personaje ficticio basado en entrevistas (herramienta Personas)

\section{Grupos focales y mapa de experiencias}

Utilizando estrategias de focus group, se realizó un experimento en el que los participantes contaban sus experiencias luego de visitar el sitio actual de Autismo Ecuador. Estudiantes de diseño gráfico, comunicación social, profesionales en psicología y familiares de personas con TEA dieron sus impresiones en cuanto a aspectos positivos, negativos y sugerencias sobre el contenido y diseño, coincidiendo en que el sitio debía mejorar. Luego del experimento realizado con el focus group, se trazó la representación de su "Mapa de experiencias" dentro del sitio. Los resultados, según cómo percibieron su visita al sitio, se pueden observar en la Fig. 5.

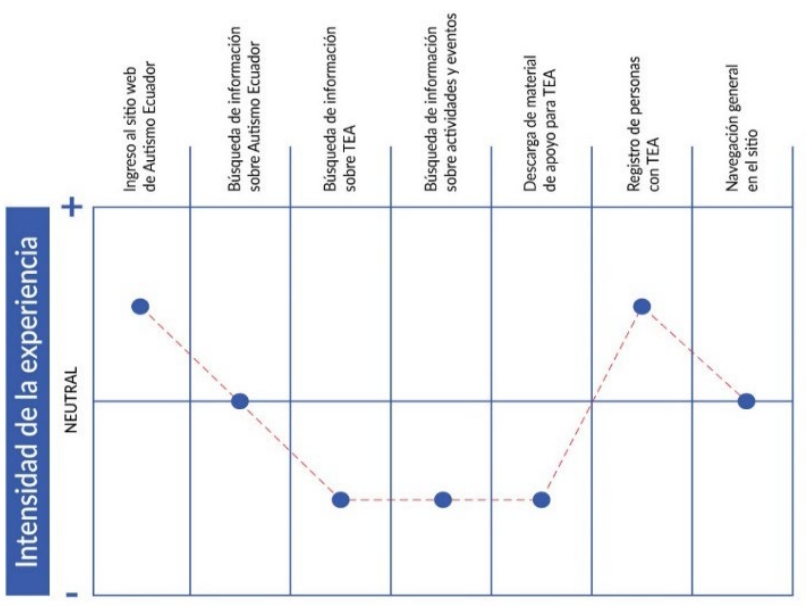

Fig. 5 Mapa de experiencias resultado del focus group 


\section{E. Insights y concepto del proyecto}

Para llegar a la determinación del concepto, se revisaron los resultados obtenidos del uso de los recursos metodológicos señalados anteriormente. En primer lugar, se codificaron y categorizaron los datos recolectados y en última instancia se contrastó la información obtenida. Durante este proceso se encontraron similitudes marcadas en los intereses y necesidades de los involucrados, con las que se logró identificar los siguientes insights:

- Padres desesperados en busca de respuestas al detectar anormalidades en el desarrollo de sus hijos en edades tempranas.

- Los padres de niños con TEA están en constante búsqueda de ayuda e información para el acompañamiento en todas las etapas de sus hijos.

- Los padres o familiares de una persona con TEA esperan encontrar toda la información que necesita en un solo sitio web y rápidamente.

- Los padres de las personas diagnosticadas con TEA necesitan sentirse comprendidos, buscan empatía y la inclusión de sus hijos en todos los ámbitos.

- Los padres de los niños y niñas con TEA están sumergidos en constante estrés y agotamiento.

A partir de los insights identificados, se concluyó que la principal necesidad de los padres de niños y niñas con TEA es tener acceso a herramientas que brinden información confiable y ayuda oportuna para sobrellevar la condición de sus hijos dentro de un entorno empático y agradable. Como resultado se determinó el siguiente concepto aplicable al presente proyecto:

- Herramienta amigable que te brinda ayuda durante todo el proceso de acompañamiento de desarrollo de tu hijo o hija con TEA para mejorar la calidad de vida.

\section{F. Propuesta de diseño y desarrollo del nuevo sitio web}

Esta sección inicia realizando un análisis del sitio web actual de Autismo Ecuador a nivel de composición, contenido y diseño como base para presentar la propuesta de un nuevo diseño, una vez identificadas las falencias visuales y comunicacionales de este sitio. Asimismo, se describen los criterios en cuanto a elementos de diseño, comunicación y experiencia de usuario que se han tomado en cuenta para el desarrollo del prototipado y maquetación del nuevo sitio web de Autismo Ecuador.

1) Análisis del sitio actual de Autismo Ecuador: El sitio web de Autismo Ecuador ${ }^{1}$ se creó en el año 2013 y hoy en día continúa con el diseño inicial, por lo que el sitio web de la asociación necesita un rediseño que le permita captar el interés de los usuarios para la difusión sobre el TEA. No obstante, los directivos de Autismo Ecuador no desean hacer cambios en el logotipo que los identifica desde entonces.

Un aspecto que llama la atención es que la dirección del sitio sugiere que abarca mucha información relacionada con el TEA en el Ecuador. Además, como afirma D'Auria [23], su extensión ".org", le otorga al sitio un alto grado de confiabilidad, por lo que el usuario ingresa con grandes expectativas de encontrar lo que busca y al final, esto no sucede, ya que es muy poco lo que el sitio puede ofrecer. Por otro lado, se observó que el sitio no se vincula con las redes sociales de Autismo Ecuador, lo que es un gran desacierto, ya que gran parte de la información que difunde la asociación es por esta vía. De la misma forma, no cuenta con un diseño responsivo, es decir, no se adapta de manera adecuada a dispositivos móviles y deja al sitio aún menos funcional.

En cuanto a diseño, se nota una gran cantidad de espacios sin utilizar, lo que se evidencia aún más si se ingresa desde un dispositivo móvil. Además, por la falta de optimización del uso de los espacios, la estructura de la página de inicio se corta, lo que provoca que la información de interés no quede visible. Es evidente que el logo de Autismo Ecuador ha sido utilizado en baja resolución, lo que no debe suceder.

Para analizar la disposición de los elementos dentro de la página de inicio, se trazó una media estructural, es decir, una línea a lo largo de la composición que la divide en dos partes iguales. Así como se observa en la Fig. 6, fue evidente notar que existe una mayor cantidad de elementos dispuestos sobre el lado izquierdo, produciendo un desbalance. De ahí que la composición no es equilibrada y no guarda armonía visual. Se observó también que no se demuestra el uso de una cuadrícula guía, dejando espacios en blanco, con elementos que no se encuentran alineados; mientras que otros, ocupan espacios excesivos.

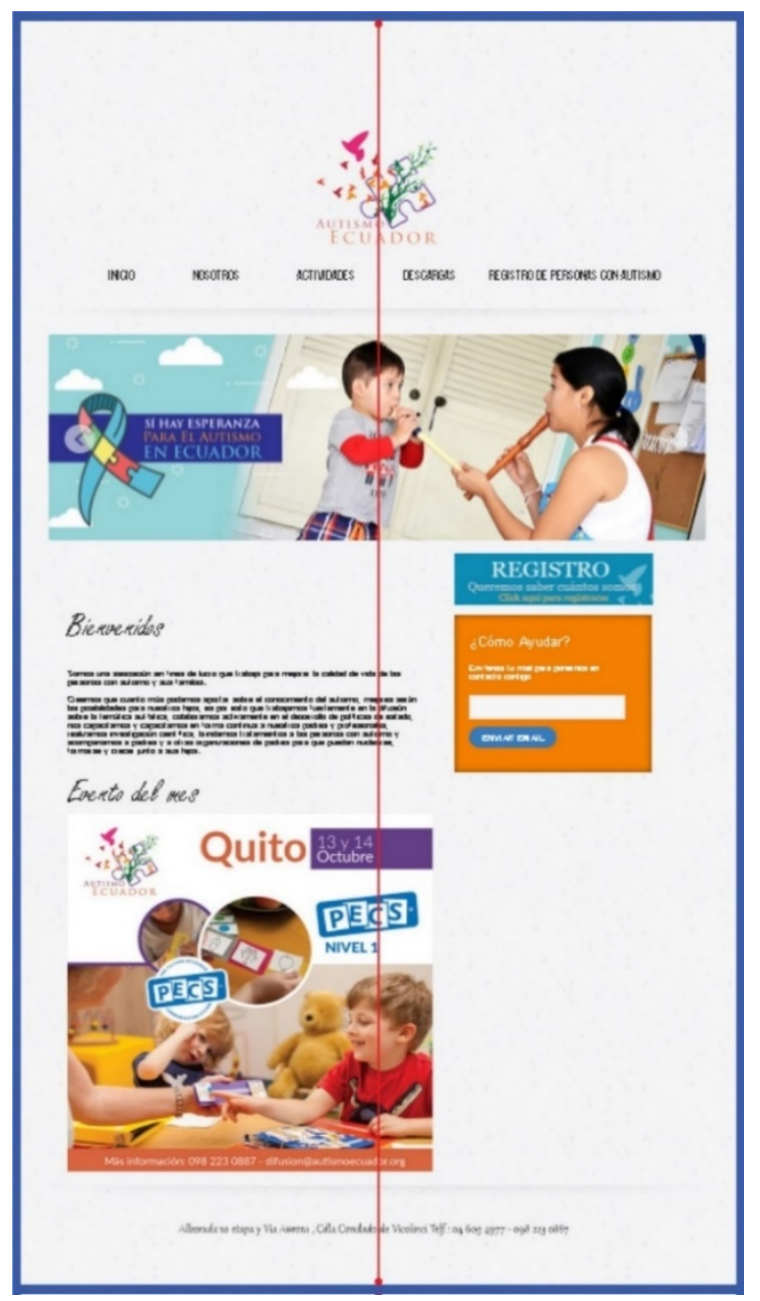

Fig. 6 Media estructural aplicada a la página de inicio del sitio

\footnotetext{
${ }^{1}$ www.autismoecuador.org
} 
En cuanto a contenido, el menú tiene pocos enlaces y ninguno de ellos muestra información acerca de los servicios que Autismo Ecuador ofrece. Tampoco cuenta con un buscador que permita al usuario encontrar información de interés de forma más directa. A más de ello, se ha colocado en esta página un enlace de "Inicio", lo que es redundante y no aporta en funcionalidad.

Con respecto a la cromática, no se determinó una paleta de colores en el sitio, sino más bien ha sido una elección de colores al azar, dado que no guardan relación con la identidad gráfica de Autismo Ecuador. Los títulos se han utilizado en color negro, al igual que en los cuerpos de texto, sin embargo, utilizar la tipografía en cursivas no es acertado. Por otro lado, a pesar de que es correcta la elección de la tipografía para los cuerpos del texto, el tamaño de la letra es pequeño y el interlineado no es el adecuado, lo cual dificulta la lectura.

Otro detalle negativo que se observó en el sitio web actual es el poco cuidado en la redacción y escritura, evidenciándose faltas ortográficas y errores gramaticales en algunos de los textos dispuestos dentro del sitio.

2) Logotipo de Autismo Ecuador: Uso y Variantes: Como se mencionó anteriormente, por pedido del cliente, se consideró el logotipo actual de Autismo Ecuador como elemento obligatorio dentro del nuevo diseño del sitio web. Por todo lo expresado, se lo tomó como punto de partida del proceso creativo que generó los elementos que componen el nuevo diseño, de manera que se mantenga la armonía visual y el concepto del proyecto. Como parte de este proceso, se determinó cuáles serían las variantes del logotipo para el presente y futuros proyectos de diseño, como vemos en la Fig. 7.

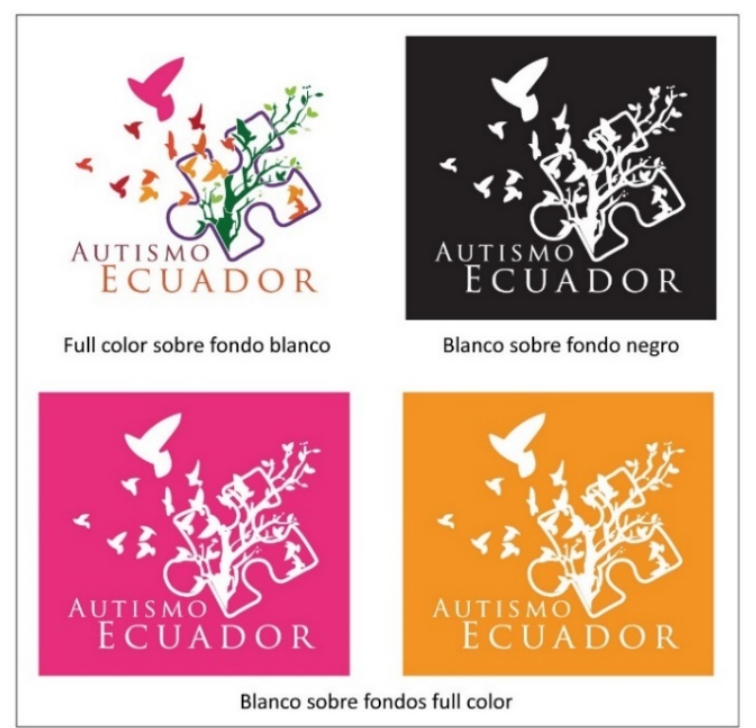

Fig. 7 Uso del logotipo de Autismo Ecuador

3) Estructura del nuevo sitio web: Para iniciar con el proceso de diseño de interfaz para un sitio web, es fundamental desarrollar la estructura que formará parte de su Arquitectura de Información (AI). Se elaboró una propuesta para la nueva estructura del sitio con la disposición de los contenidos sugeridos y a partir de la cual se diseñaron las interfaces de la página de inicio o home y páginas internas. A medida que avanzaba el desarrollo del proyecto, esta estructura se fue modificando con el fin de mejorar la experiencia del usuario, quedando como resultado final la que vemos en la Fig. 8.

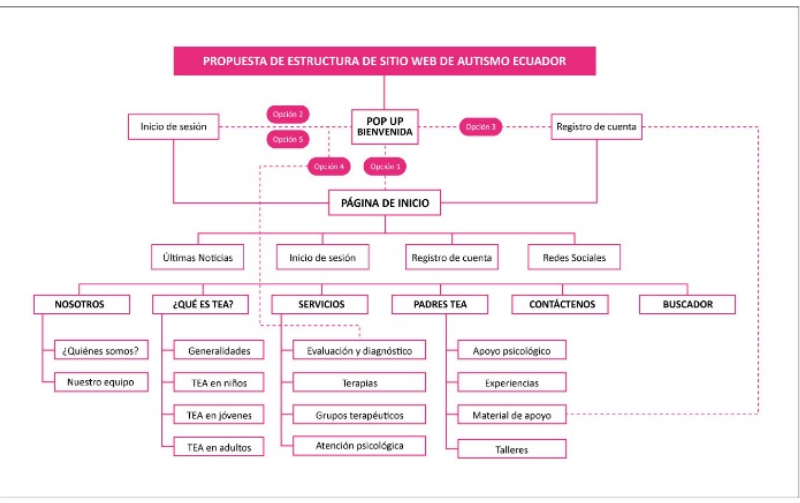

Fig. 8 Propuesta para la estructura del nuevo sitio web

A partir de esta estructura, y por medio de un proceso de bocetaje, se desarrollaron plantillas de diagramación, ya que, como afirma Harrell [17], se considera el esbozo y la maquetación como elementos esenciales del proceso del diseño web. Se definió un formato vertical delimitando los espacios para los elementos de la página de inicio, tomando en cuenta los principios de equilibrio y jerarquía visual y además que el diseño debe adaptarse a dispositivos móviles quedando definida la plantilla que vemos en la Fig. 9.

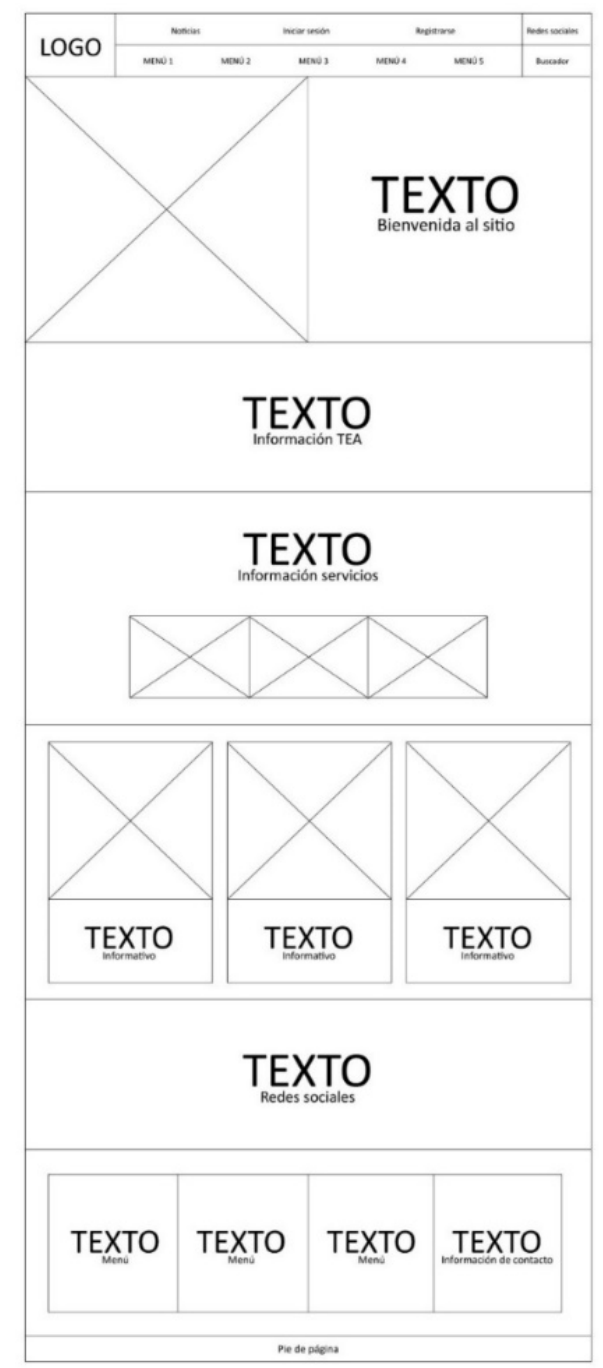

Fig. 9 Plantilla de diagramación para la página de inicio 
4) Paleta de colores: En función de las herramientas moodboard y coolboard elaboradas previamente, se conoce que el color por excelencia de la comunidad TEA es el azul, no obstante, se optó por el uso de una paleta de colores que identifique a Autismo Ecuador. Esto permitió mantener la armonía visual dentro del sitio y, además, son tonalidades que evocan el entorno amigable y cálido que se busca transmitir al usuario. Para complementar este concepto, se incorporó una tonalidad gris, como se observa en la Fig. 10, que se utilizó principalmente en textos. Dado que es un color que contrasta y a la vez equilibra y neutraliza los tonos brillantes y que le otorga sobriedad al sitio.

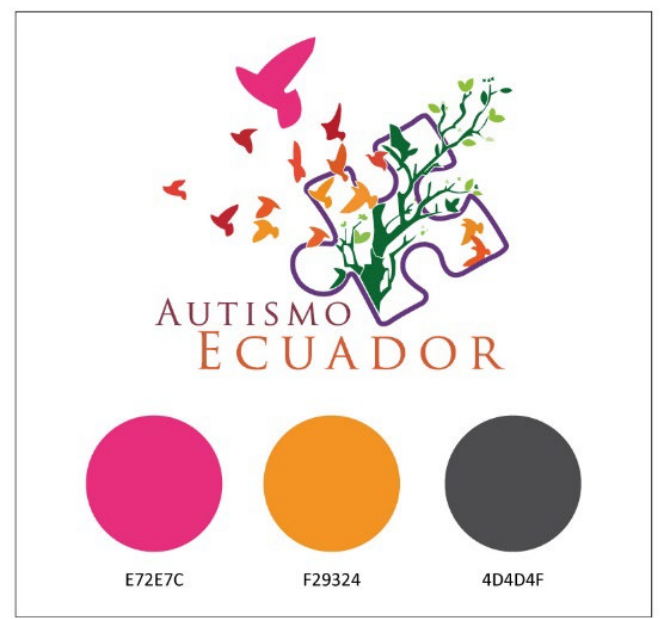

Fig. 10 Paleta de colores para el sitio

5) Tipografía: Se escogió Lato, una tipografía sans serif o de palo seco, con características que se adaptan a las necesidades de la propuesta, como la legibilidad y versatilidad. Tiene una gran variedad dentro de su familia tipográfica, como se observa en la Fig. 11, por lo que no fue necesario combinarla con otra tipografía y aportó armonía visual al diseño. Cabe destacar que, además de ser empleada para los textos, la tipografía también será tomada como un elemento para el diseño en algunos casos.

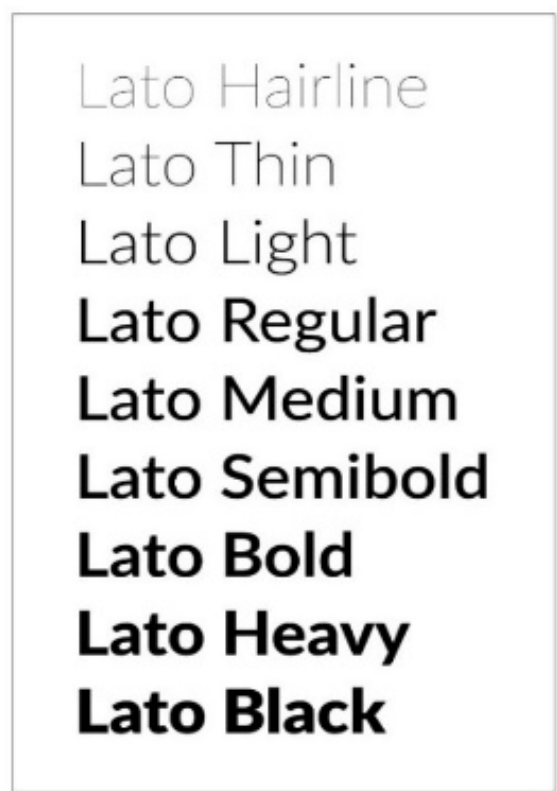

Fig. 11 Familia tipográfica utilizada en el nuevo diseño del sitio
6) Pop-up o intro de bienvenida: La propuesta de estructura del nuevo diseño tiene como punto de partida un pop-up de bienvenida, es decir, el usuario no ingresa directamente a la página de inicio; en su lugar, a través de una ventana de recibimiento, debe elegir la tarea que va a realizar dentro del sitio web a modo de accesos directos. Para este fin se diseñó un menú flotante en el que el usuario puede escoger entre cinco opciones según sus necesidades.

Esto permite el uso de atajos de navegación (shortcuts) llevando directamente al usuario a los contenidos de su interés o continuar con una navegabilidad completa por el sitio. Para ejemplificar, si el usuario escoge la opción 1, como se observa en la Fig. 12, se dirige a la página de inicio del sitio y puede comenzar a navegar.

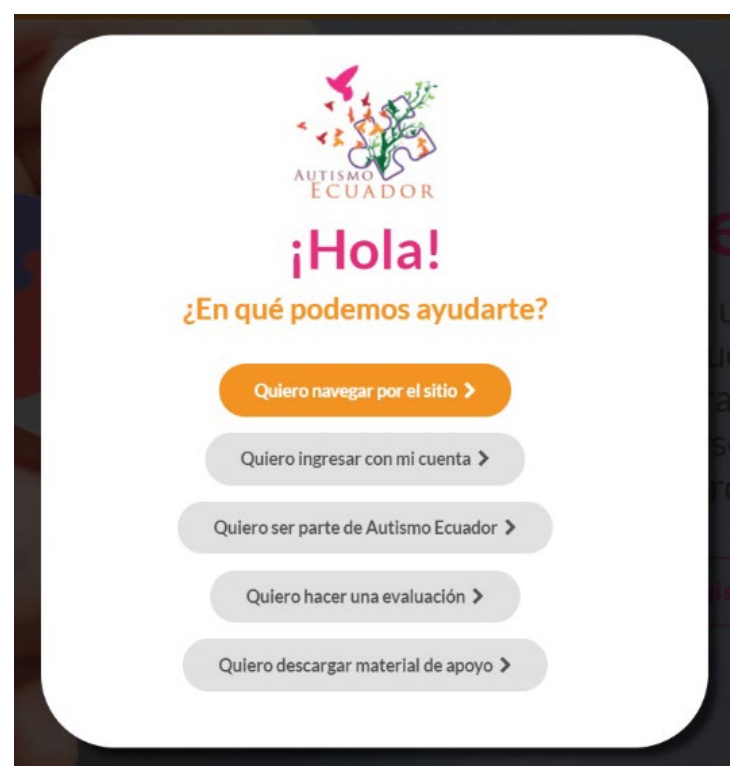

Fig. 12 Pop-up de bienvenida al sitio web

Para las opciones 2 y 3 respectivamente, se diseñaron los pop-ups que corresponden al acceso al sitio por medio de una cuenta ya creada o al registro de una en caso de no tenerla, como se puede observar en la Fig. 13.

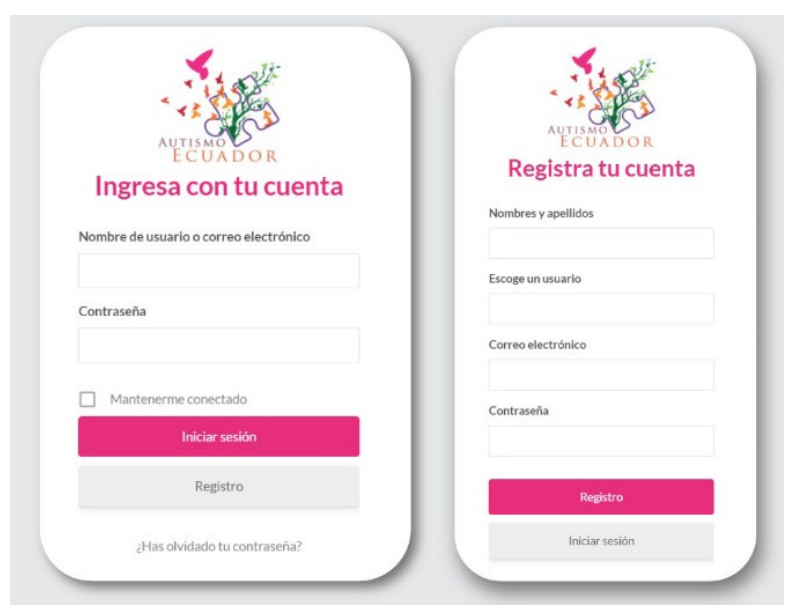

Fig. 13 Pop-ups para inicio de sesión al sitio y registro de cuenta

Estas opciones se implementaron con la finalidad de otorgar al usuario una experiencia grata y un sentido de pertenencia a la comunidad. Al tener el usuario una cuenta, no solo accede a contenidos exclusivos, sino que pasa a formar parte de una comunidad. 
7) Prototipo para la página de inicio o home: De todas las fases, esta es la que suele recibir más atención y también se considera la más divertida [17], ya que es aquí donde se desarrollan los diseños de la interfaz visual, los esquemas de navegación y los patrones de diseño iniciales para la experiencia general y donde se prepararon los escenarios para el resto del proceso.
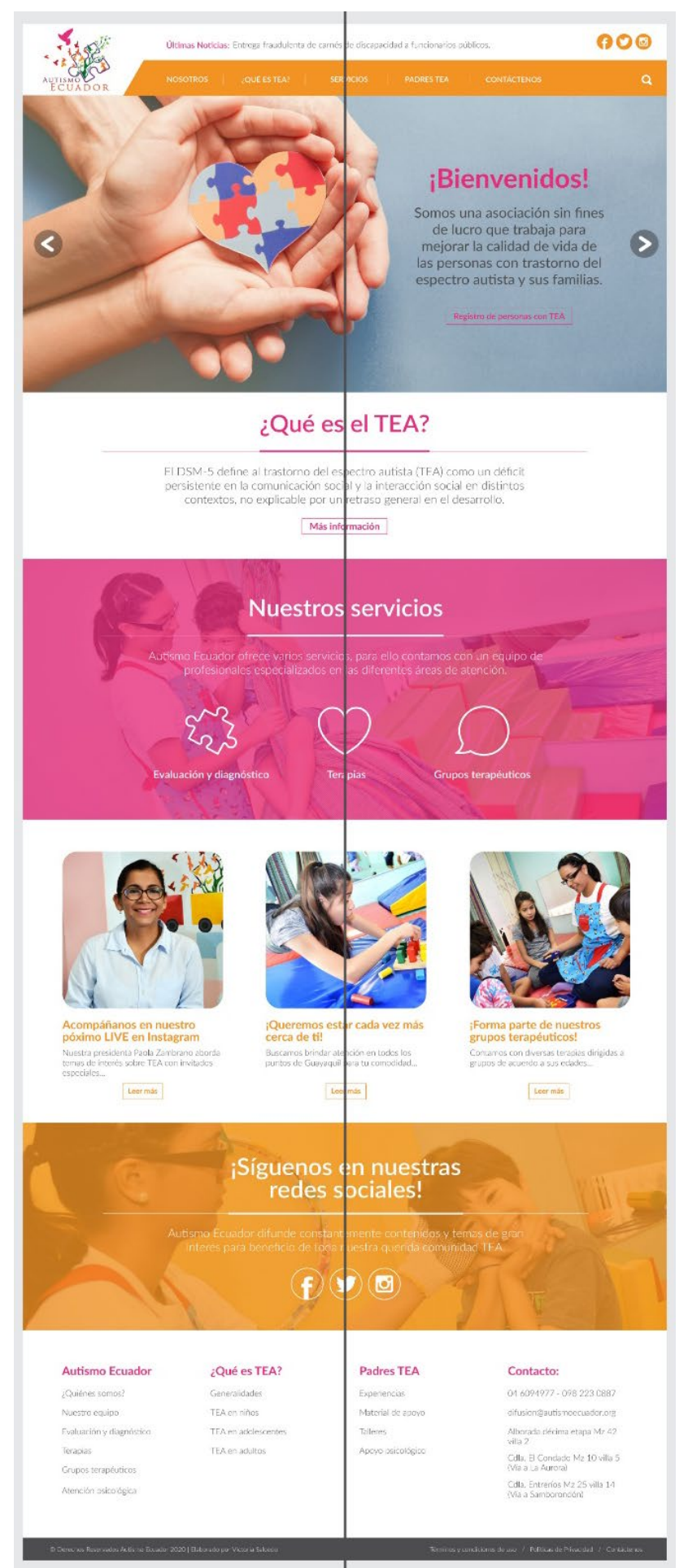

Fig. 14 Diseño de Página de inicio o home y media estructural

De acuerdo con el concepto del proyecto, se diseñó una interfaz que recibe y da la bienvenida al usuario en un entorno cálido y amigable. Por otro lado, si bien se buscó que el sitio presente un sistema de usabilidad sencillo, esto no significó alejarse de las tendencias que hoy en día se utilizan para el diseño de sitios web.

En principio se estableció que se aprovecharía todo el espacio de la pantalla para implementar el diseño, por lo que, según la opinión de expertos, se eligió el flat design. Esto consiste en el uso de imágenes que ocupen todo el ancho de la pantalla para lograr un alto impacto visual, complementado con el uso de formas geométricas, imágenes vectoriales, íconos y botones fantasma. Además, se consideró un menú fijo que se mantendrá visible en la parte superior, haciendo al sitio web más accesible. A esto se le suma el uso de parallax, con el que se le dio relevancia a la fotografía mediante el movimiento en capas, dando una sensación de profundidad. Las características antes mencionadas podrán ser visualizadas a lo largo de la página de inicio a medida que el usuario utilice el sistema de scrolling o desplazamiento hacia abajo.

En la Fig. 15 se puede observar, por medio de una media estructural, que la disposición de los elementos se percibe dentro de una composición simétrica y equilibrada. Siguiendo las recomendaciones de expertos en cuanto a cómo los usuarios miran los elementos de un sitio web, se hizo el correcto uso de la jerarquía visual de estos elementos ubicándolos acorde a los espacios dispuestos en el diseño de la plantilla estructural y se logró una armonía visual en la página de inicio del sitio.

8) Prototipo para páginas internas del sitio web: Bajo la misma estructura y proceso de desarrollo de la página de inicio, se elaboró una plantilla de diagramación para las páginas internas, como se observa en la Fig. 15; esta puede estar sujeta a pequeñas variaciones según el contenido que se vaya a presentar en cada sección del sitio, sin que afecte al diseño propuesto.

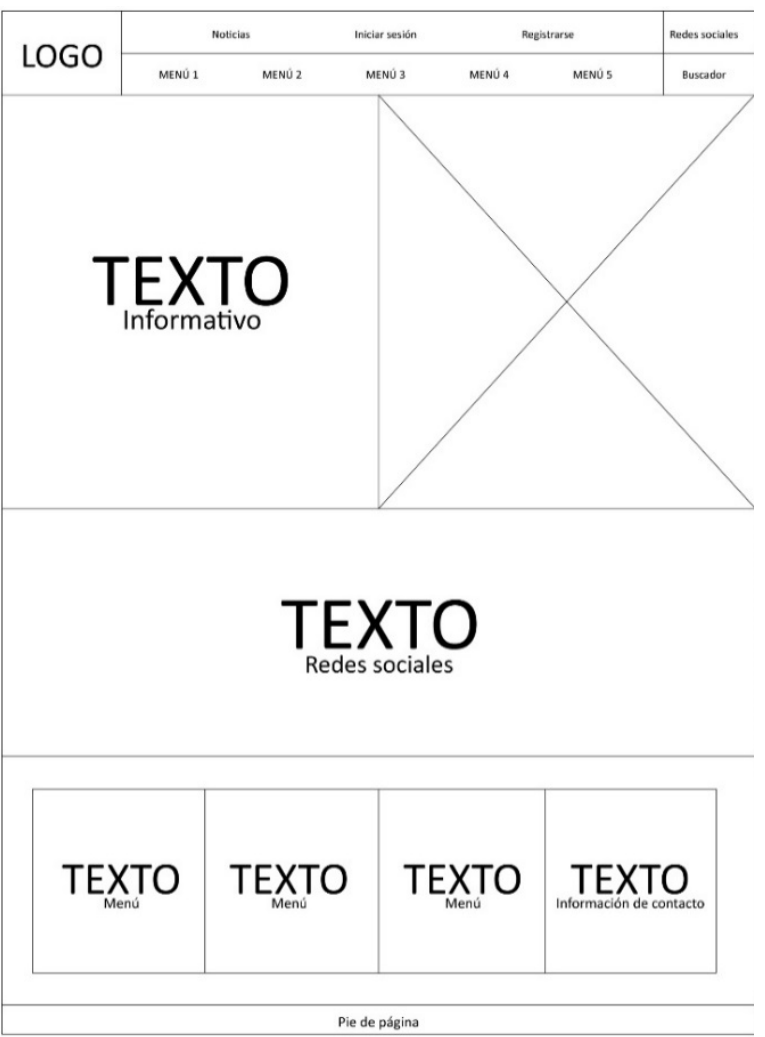

Fig. 15 Diseño de plantilla para páginas internas 
Como se observa en la Fig. 16, se diseñó la página interna "¿Quiénes somos?", bajo los criterios de diseño establecidos en el proceso creativo para el desarrollo de la composición del diseño de interfaz planteado para la página de inicio o home, con el fin de mantener la misma línea gráfica dentro del sitio.

Para aportar accesibilidad a las páginas internas, se mantienen la barra de menú, el footer y la sección de redes sociales. Otro aspecto que se tomó en consideración con respecto a la composición es el ancho de los cuerpos de texto, debido a que los expertos recomiendan no exceder los 500 pixeles, para efectos de no abrumar al usuario con grandes bloques de texto. En su lugar, se da al usuario la opción de escoger si sigue leyendo o no el texto de acuerdo a sus intereses. Esto se logró mediante la incorporación de botones fantasma a los que el usuario puede reaccionar intuitivamente dando clic sobre estos.

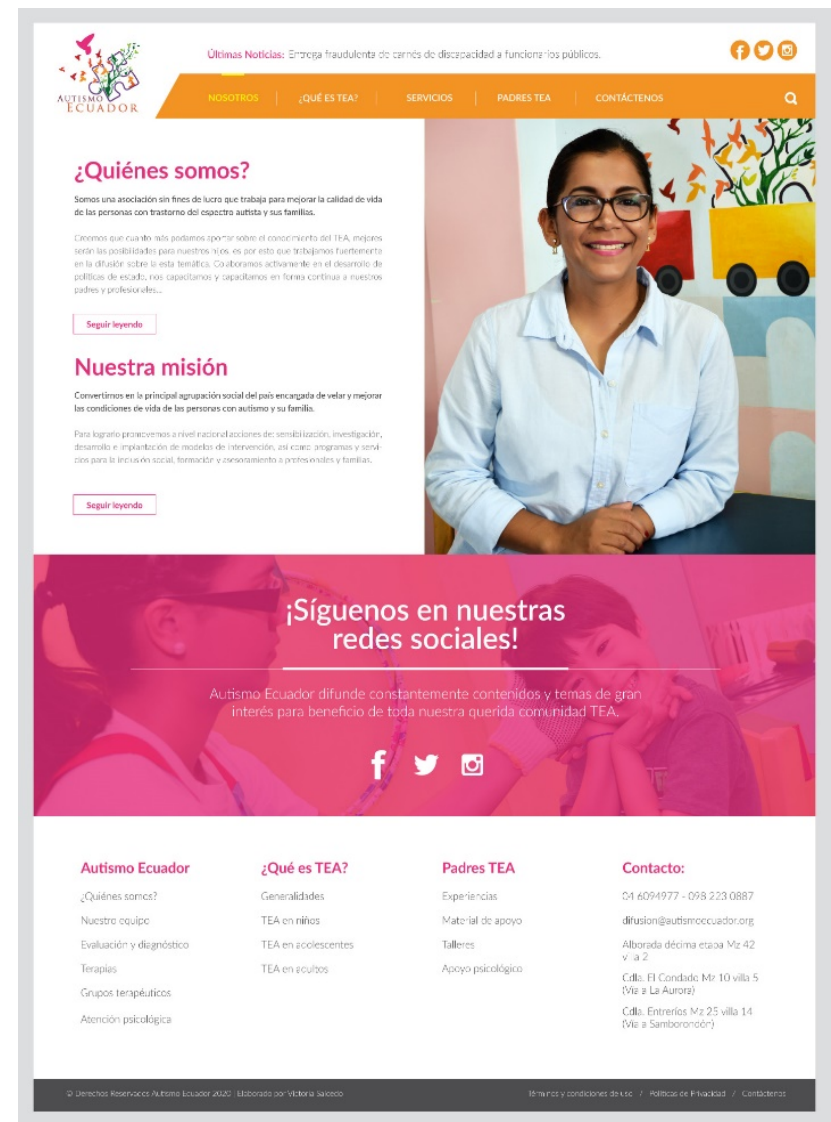

Fig. 16 Ejemplo de diseño de páginas internas del sitio

9) Diseño responsivo para el sitio web de Autismo Ecuador: Como se especificó al inicio de este artículo, esta propuesta de rediseño debía contar con un diseño adaptativo a varios dispositivos, en especial, móviles. Para ello se elaboró una plantilla de diagramación inicial cuya estructura y diseño debían tener dentro de sus características principales, la capacidad de adaptarse a un formato vertical de tal forma que pueda ajustarse al ancho de pantallas más pequeñas, sin que se vea afectado el concepto de diseño determinado para el sitio.

Como se observa en la Fig. 17, se adaptó tanto la estructura como el diseño a un formato menor, en este caso 400 pixeles, que es la medida comúnmente utilizada en estos casos.
El cambio más evidente para esta adaptación es el uso de un menú hamburguesa, lo que ayuda a suprimir el uso del espacio y aporta a la usabilidad del sitio en móviles. De igual manera, se incorporaron elementos intuitivos como flechas, los textos se acortaron en algunos casos y se le dio más espacio entre elementos de manera que no interfieran en la navegabilidad del usuario al pulsar sobre alguno de los enlaces.
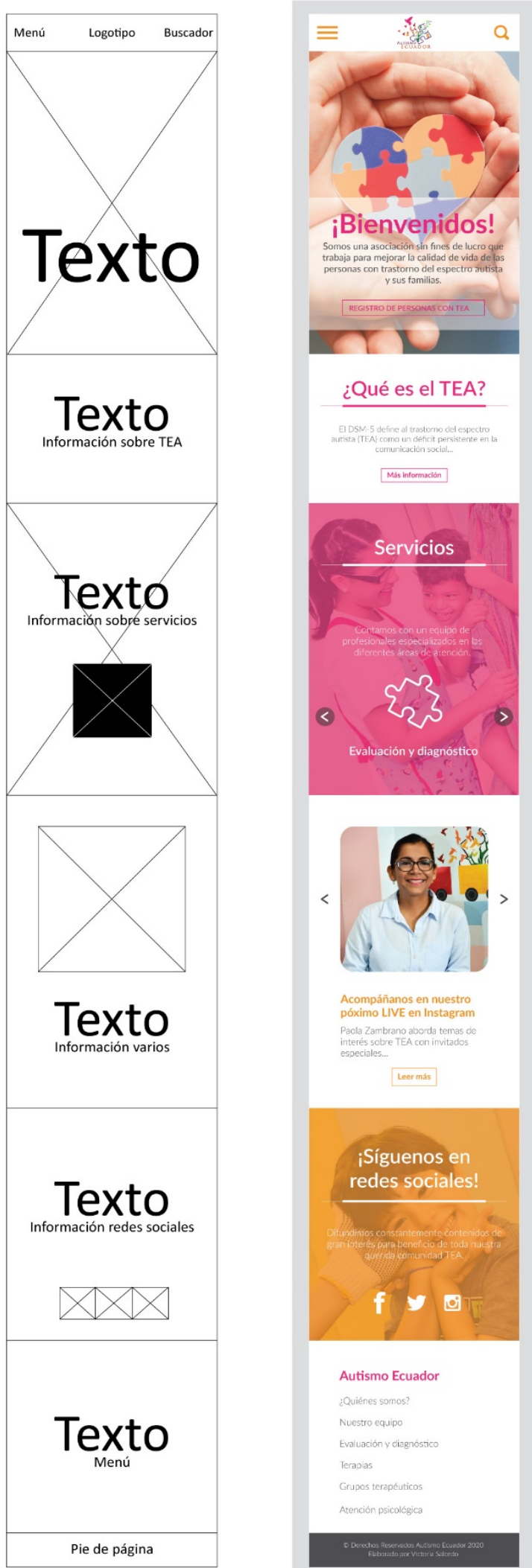

Acompáñanos en nuestro póximo LIVE en Instagram Pacla Zambrano aborda temas de
interés sobre TEA con invitados Leer mis

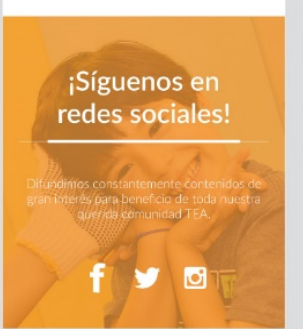

Autismo Ecuador ¿Quiénes somos? Nuestro equipo Evaluación y ciagnóstico Terapias

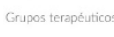

Atención psicolobica

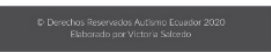

Fig. 17 Plantilla y estructura para el diseño adaptativo 


\section{PRESENTACIÓN DE RESULTADOS Y DISCUSIÓN}

Como resultado del proyecto, se presenta un sitio web renovado que, además de ser funcional, cuenta con un diseño de mejor nivel comunicacional y atractivo visual. El sitio se enlaza con sus redes sociales y se adapta a diferentes dispositivos, lo que le dará a Autismo Ecuador mayor visibilidad. (Ver Fig. 18)

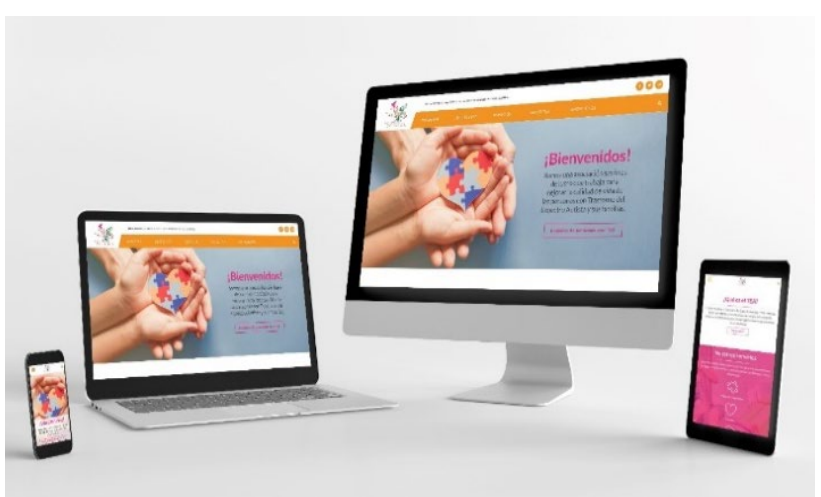

Fig. 18 Mockups del prototipo del sitio en diferentes dispositivos

En esta propuesta, además del diseño y desarrollo de prototipos de una nueva interfaz para el sitio web, se hizo la implementación como resultado final del diseño. Para ello, se realizó el proceso de maquetación bajo el gestor de contenidos o Content Management System (CMS) WordPress 5.5.

Al tener como resultado un sitio web con diseño responsivo, la visualización de la propuesta del nuevo diseño del sitio web de Autismo Ecuador implementada, la página de inicio y varias páginas internas, se puede realizar a través de computadoras de escritorio, laptops y dispositivos móviles ingresando a la dirección temporal: www.autismoecuador.org/nuevo-sitio/

\section{A. Usabilidad del nuevo sitio de Autismo Ecuador}

En caso de que llegue a implementarse este nuevo diseño del sitio, hay que recalcar los aspectos en cuanto navegabilidad que se tomaron en cuenta para el desarrollo del prototipo, ya que uno de los objetivos del sitio es que utilizarlo resulte sencillo e intuitivo para todo tipo de usuarios, de manera que se amplíe su accesibilidad. En este caso, se consideró la amplia diversidad del público objetivo establecido, del que incluso forman parte las mismas personas diagnosticadas con TEA.

Con este antecedente se determinó que al momento de haber ingresado el usuario a la página de inicio pueda navegar desplazándose hacia abajo y hacia arriba intuitivamente por medio del scrolling. Así mismo, puede realizar su navegación a través de la barra de menú, ubicada en la parte superior del home, dando clic sobre los enlaces que lo dirigirán a las secciones de la página de inicio o a las páginas internas, según lo requiera.

De igual manera, en su recorrido dentro de la página de inicio, el usuario se encontrará con más enlaces, sean estos en forma de texto o como íconos, a los que puede acceder dando clic sobre ellos. Este sistema de navegación se aplica también a la versión adaptada para los dispositivos móviles.

\section{B. Manual de usuario para el nuevo sitio web de Autismo Ecuador}

Por medio de este manual se presenta el detalle de los resultados obtenidos del desarrollo e implementación del prototipo realizado en este proyecto para el nuevo diseño del sitio web de Autismo Ecuador, siguiendo los criterios de diseño establecidos durante el proceso creativo y bajo la validación de profesionales y expertos relacionados con diseño gráfico, diseño web y TEA.

\section{Acceso al sitio web}

A continuación, se explica cómo acceder al sitio web a través de un navegador:

1. En el explorador, se ingresa la dirección del sitio web: www.autismoecuador.org, como se muestra en la Fig. 19.

2. Una vez escrita la dirección de Autismo Ecuador, se presiona el botón "enter" o "entrar" de su teclado e inmediatamente se dirigirá al sitio en donde aparecerá un pop-up o intro de bienvenida.

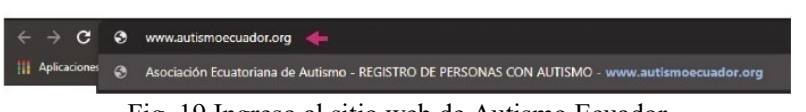

Fig. 19 Ingreso al sitio web de Autismo Ecuador

\section{Pop-up de bienvenida al usuario}

Antes de ingresar a la página de inicio aparece un menú flotante con varias opciones. A continuación, se detalla a dónde dirige cada una de ellas.

1) Quiero navegar por el sitio: Esta primera opción, como se observa en la Fig. 20, dirige al usuario a la página de inicio o home del sitio web.

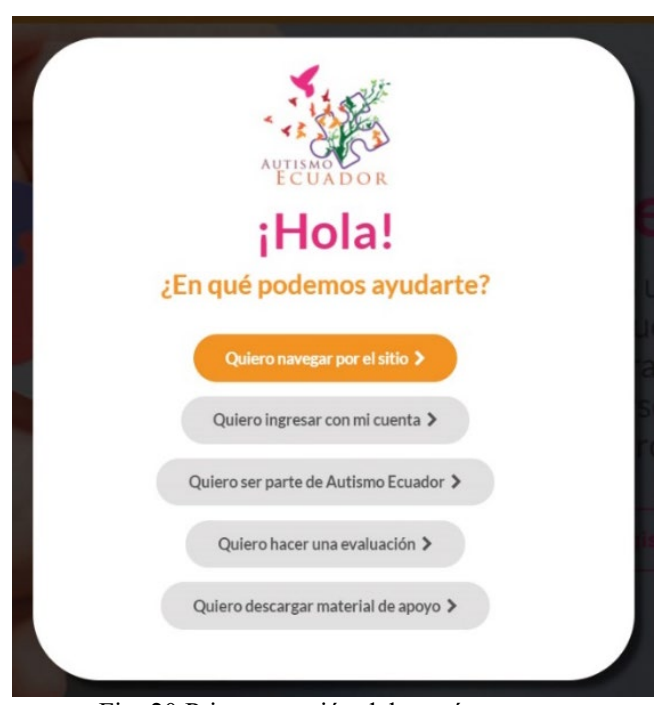

Fig. 20 Primera opción del menú pop-up.

2) Quiero ingresar con mi cuenta: La segunda opción del menú es para el usuario que ya ha creado su cuenta en el sitio por lo que, al dar clic, aparece un pop-up en el que se le pide ingresar con su usuario y contraseña, de esta forma el usuario accede a los contenidos que son exclusivos para los miembros de la comunidad Autismo Ecuador. En el caso de que un usuario presione esta opción 
sin tener una cuenta, el botón "Registro" le permite acceder al formulario para crear una cuenta. (Ver Fig. 21)

3) Quiero ser parte de Autismo Ecuador: Esta opción le permite al usuario nuevo crear su cuenta para formar parte de la comunidad de Autismo Ecuador por medio de su sitio web. Para esto, se solicitan algunos datos de registro, como su nombre completo, un usuario, el correo electrónico y contraseña. (Ver Fig. 21)

En el caso de que un usuario que ya tiene cuenta ingrese por error a esta opción, por medio del botón "Iniciar sesión” puede ingresar con su usuario y contraseña.

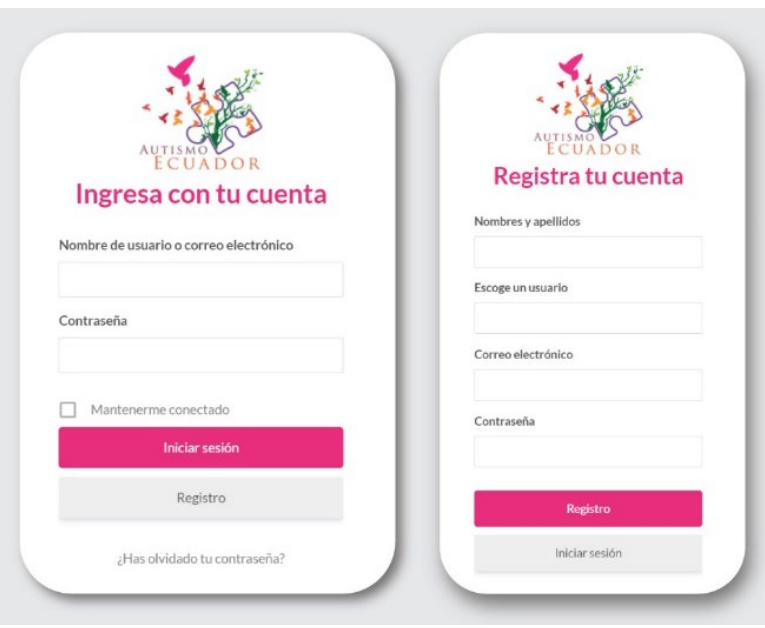

Fig. 21 Opción 2 y 3 del menú pop-up

4) Quiero hacer una evaluación: Este enlace está dirigido a los usuarios que deseen acceder directamente a una consulta para realizar una evaluación psicológica especializada al niño, niña, joven o adulto para confirmar o descartar un diagnóstico relacionado con los trastornos del espectro autista. (ver Fig. 22)

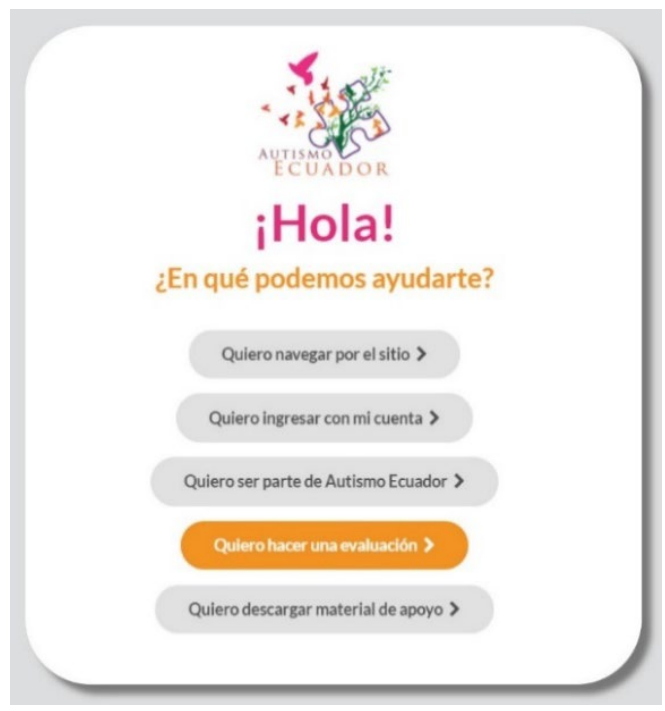

Fig. 22 Opción 4 del menú pop-up

5) Quiero descargar material de apoyo: Por medio de esta opción el usuario puede acceder a material de apoyo, tips y guías prácticas para aplicar durante el acompañamiento de su familiar con TEA desde casa. Este enlace corresponde a "Padres TEA" y es contenido exclusivo para quienes hayan creado una cuenta. En caso de ser un usuario nuevo y dar clic en esta opción, el sitio web inmediatamente le solicita ingresar con su cuenta y, en caso de no tenerla, crear una.

\section{E. Página de inicio o home}

El usuario puede navegar por el home utilizando el scroll, desplazándose hacia abajo y también por medio de los enlaces del menú. En la parte superior, tenemos: el logo de Autismo Ecuador sobre el lado izquierdo, seguido de los enlaces Últimas noticias, y redes sociales. Luego, la barra de menú, que incluye los enlaces y la opción de búsqueda dentro del sitio, como vemos en la Fig. 23.
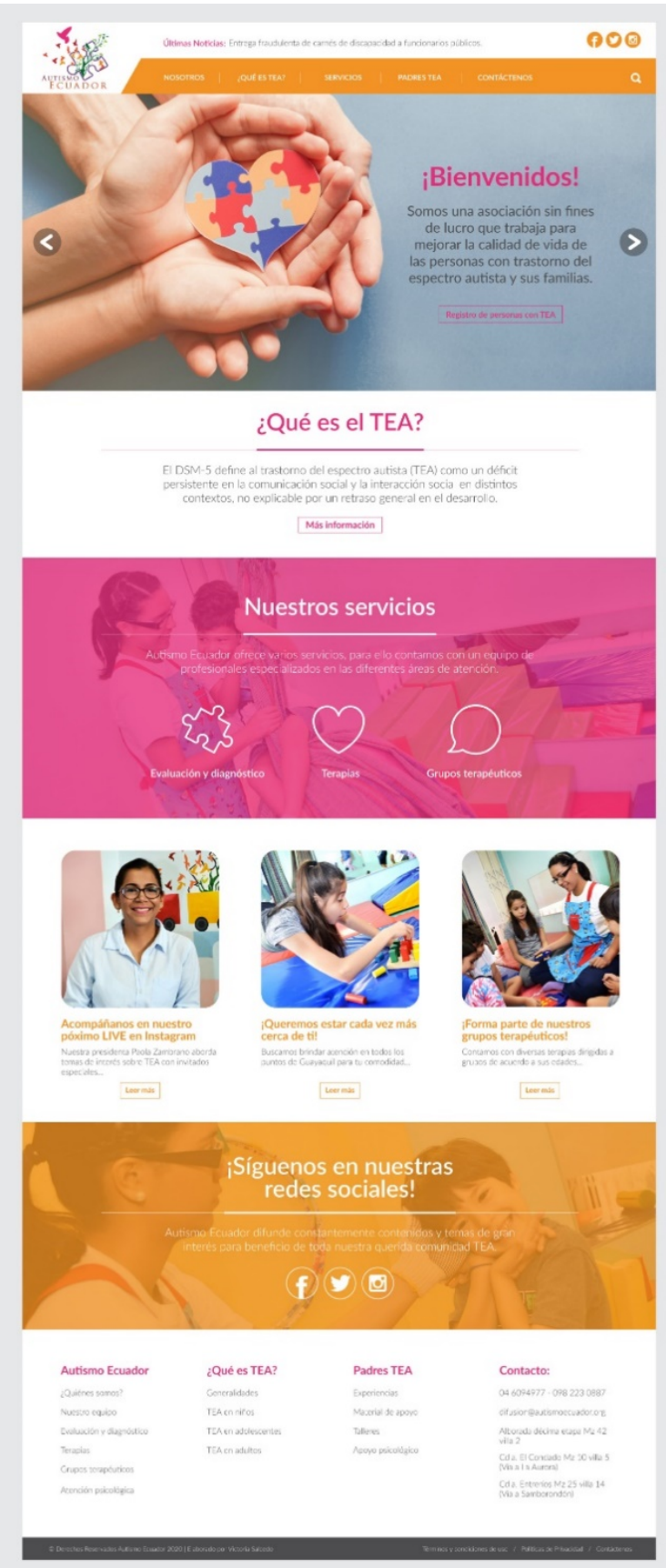

Fig. 23 Página de inicio de Autismo Ecuador

1) Banners principales: Tenemos tres banners que se presentan a manera de sliders. Estos se mostrarán automáticamente cada tres segundos o presionando las flechas que están ubicadas a los extremos de las imágenes. Asimismo, si el cursor se encuentra sobre la imagen, esta 
se mantiene, permitiendo la lectura de los textos al usuario. Cada una de estas sliders dirigen al usuario a páginas internas.

El primero, como se observa en la Fig. 23, es el que da la bienvenida al usuario y el botón de registro lo dirige a un formulario donde podrá ingresar los datos de su familiar con autismo a la base de datos.

El segundo, como se observa en la Fig. 24, invita al usuario nuevo que aún no es miembro de la comunidad Autismo Ecuador a registrarse y crear su cuenta, es decir, al presionar el botón "Regístrate aquí", lo redirige al formulario de registro.

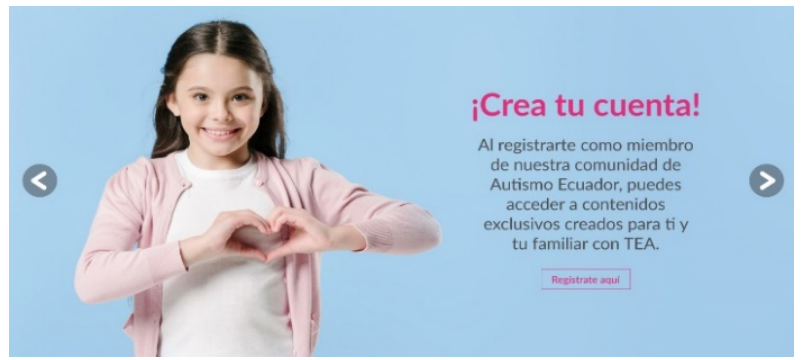

Fig. 24 Banner "Crea tu cuenta"

El tercer banner, como vemos en la Fig. 25, es un enlace al contenido correspondiente al material de apoyo. Es decir, al dar clic en el botón "Más información", si el usuario ya tiene su cuenta, accede directamente a este contenido. Caso contrario lo invita a crear su cuenta de Autismo Ecuador para poder hacerlo.

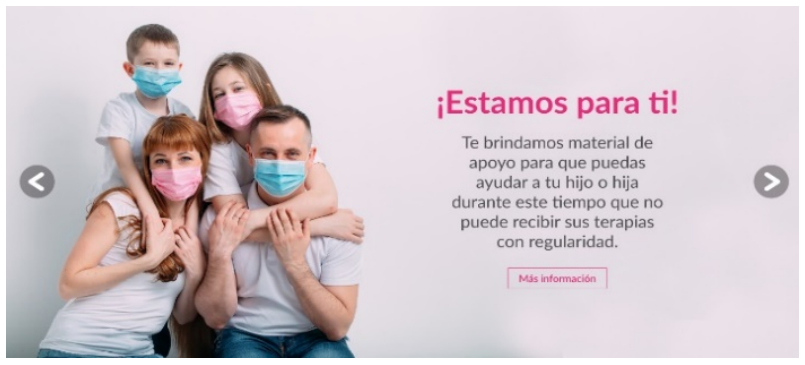

Fig. 25 Banner "Estamos para ti"

2) Sección ¿Qué es TEA?: Si el usuario continúa su navegabilidad por medio del scroll, se encuentra con este espacio en donde, con una breve descripción, se lo introduce a la definición del TEA, como observamos en la Fig. 26. Si el usuario desea ver más información, accede a la página interna correspondiente a este enlace por medio del botón en la parte inferior de esta sección.
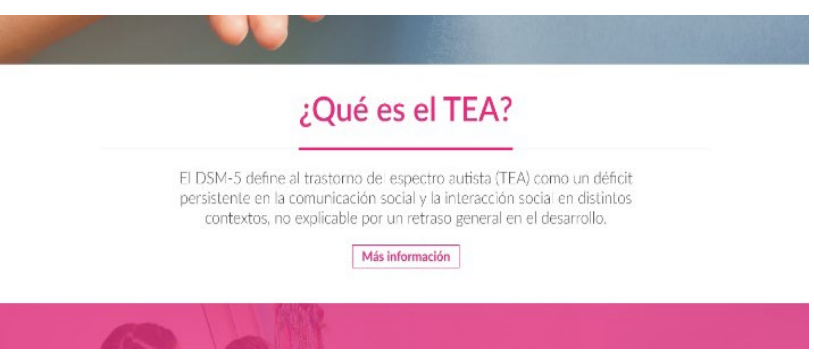

Fig. 26 Sección “¿Qué es TEA?”

3) Sección nuestros servicios: Al seguir navegando hacia abajo, en esta sección, el usuario puede acceder a la información acerca de los servicios que ofrece Autismo Ecuador al dar clic en cada uno de los íconos, como vemos en la Fig. 27.

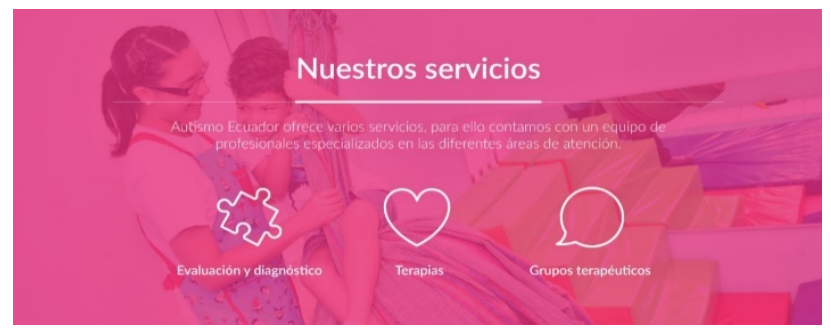

Fig. 27 Sección "Nuestros servicios"

4) Sección varios: En este bloque se invita al usuario a acceder a algunos enlaces de la página. En cada uno de los enlaces se presenta un botón de "Leer más" que redirige al usuario al contenido que escoja, como se puede observar en la Fig. 28.

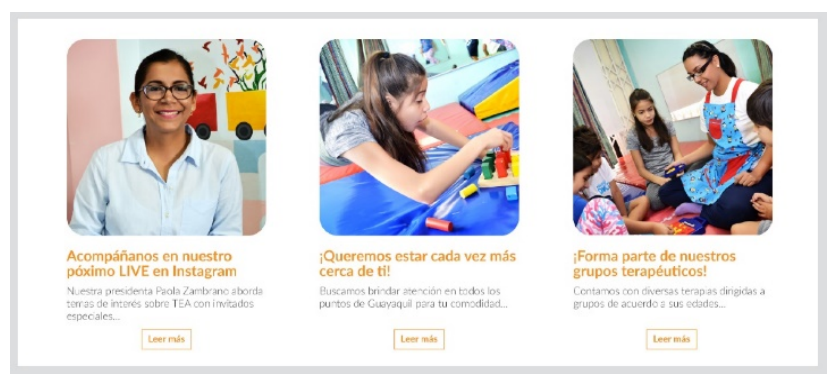

Fig. 28 Sección "Varios"

5) Sección ;Síguenos en redes sociales!: El sitio web tiene como objetivo la permanente difusión de contenidos sobre el TEA. Por lo que se hace énfasis en los enlaces a las redes sociales, invitando al usuario a interactuar en ellas. (Ver Fig. 29)

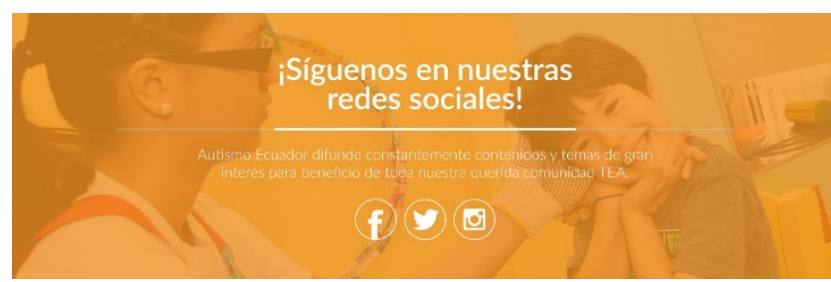

Fig. 29 Sección "Redes sociales"

6) Pie de página o footer: En el pie de página o footer, el usuario puede encontrar información de contacto de Autismo Ecuador y enlaces relevantes (ver Fig. 30). El usuario puede regresar al inicio de la página por medio de la flecha en la parte inferior derecha.

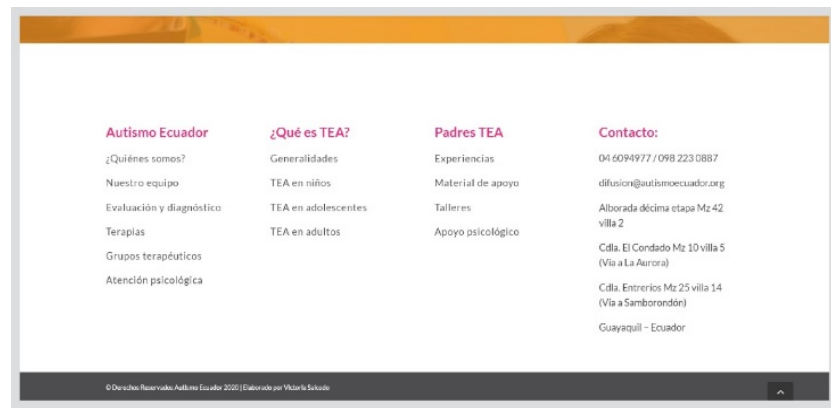

Fig. 30 Pie de página o footer 


\section{F. Páginas internas del sitio}

El enlace "Nosotros" es el primero que el usuario encuentra dentro de la barra de menú. Al dar clic sobre este, la etiqueta se vuelve de color amarillo y se despliega el menú que muestra los enlaces de las páginas internas, como se puede observar en la Fig. 31.

1) ¿Quiénes Somos?: El usuario ingresa a esta página por medio de la barra de menú dando clic en el enlace "Nosotros" y escogiendo la primera opción. En esta página se muestra información de Autismo Ecuador y se maneja el mismo esquema de navegabilidad que en la página de inicio.

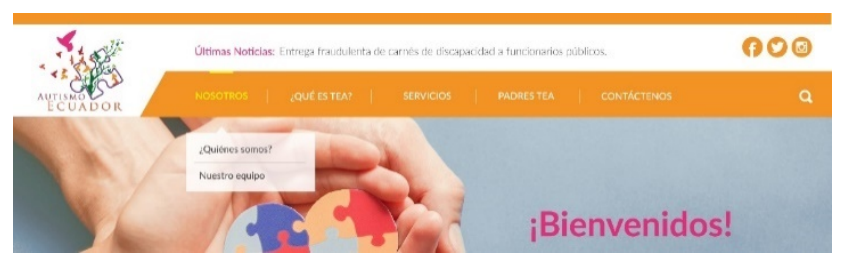

Fig. 31 Menú Nosotros

\section{CONCLUSIONES Y TRABAJOS FUTUROS}

Este trabajo se enfoca en la estructura y maquetación de páginas web con diseño adaptativo, el caso se orienta al desarrollo de un sitio web para un público involucrado a personas con TEA. Se ha logrado mostrar la funcionalidad y navegabilidad del sitio, confirmando la viabilidad del proyecto como un estudio bien informado siguiendo un proceso metodológico de investigación sobre el diseño, que soporta técnica y estéticamente lo propuesto. El diseño propuesto para el desarrollo e implementación del sitio web es responsivo, logrando que se adapte sin problemas a otros dispositivos, como teléfonos móviles y tabletas, lo que potencializa enormemente su alcance. Otro aspecto por resaltar es que se toman en cuenta funcionalidades que le permiten al sitio ser más accesible.

En el diseño de un sitio web, gran parte del avance y el éxito de su desarrollo, depende de la información proporcionada por el cliente y nuevas ideas o requerimientos que surgen en el proceso. En ocasiones, esto causa que los plazos de entrega puedan extenderse. Las sugerencias de nuevas ideas podrían continuar generalmente hasta obtener la aprobación de la información con la que se registren los contenidos para el sitio web (copywriting). Por lo que se hace relevante indicar que no todos los contenidos presentados en una propuesta de diseño se consideran como definitivos hasta su completa implementación. En el caso del proyecto presentado con enfoque en un diseño comunicacional y visual para TEA, se enfatiza que, para completar su implementación, se debe contar además con la colaboración de un programador web. Este debe realizar un trabajo conjunto con el diseñador y cliente para la puesta en marcha del sitio en tiempo real y probar todas sus funcionalidades.

Durante el desarrollo de un sitio web, se deben definir los protocolos de implementación y los contenidos que se van a mostrar en cada uno de los enlaces en un documento de Especificación de Requerimientos (ER). Se toma el desarrollo de la propuesta del diseño del sitio como marco previo para establecer las restricciones iniciales que pueda presentar su implementación.

\section{A. Trabajos futuros}

Se indicó que en la actualidad el sitio web de Autismo Ecuador se registra entre los primeros lugares de acceso a nivel local, evidenciado en el motor de búsqueda de Google, pero las visitas son efímeras. Con el diseño propuesto, se busca la permanencia del usuario dentro del sitio. Este diseño se enfoca en buscar que el usuario se sienta bien informado y cómodo en su manejo y navegación de fácil uso. Sin embargo, en su futuro proceso de implementación se debe considerar complementar la programación e implementación del sitio con la aplicación de SEO, ya que este puede aportar enormemente a su visibilidad.

El proyecto presentado en este artículo fue desarrollado en el marco de una pandemia mundial, lo que impulsó la adaptación a la virtualidad con un modelo investigativo y metodológico que, junto con la creatividad, permitió el desarrollo de una propuesta que cumple con los objetivos planteados. Sin embargo, hay que señalar que las restricciones ocasionadas por la emergencia limitaron parcialmente las ideas que surgieron para el desarrollo de la propuesta, como, por ejemplo, el caso de sesiones fotográficas nuevas en las que participen activamente los miembros de Autismo Ecuador interactuando con los niños, niñas, jóvenes y padres de manera que estas formen parte de los banners principales del nuevo diseño del sitio web. Por tanto, se recomienda la realización de futuras sesiones fotográficas para añadir imágenes actualizadas y reales, ya que esto otorgará mayor credibilidad al sitio y generará confianza. A su vez, este repositorio se debe considerar como un banco de imágenes disponible para uso del cliente.

También, es importante realizar validaciones al sitio web en cuanto a la accesibilidad para personas con diferentes discapacidades, lo cual puede complementar a futuro la ampliación de opciones en diseño para este tipo de páginas web.

\section{RECONOCIMIENTOS}

El presente artículo estructura y describe en detalle, como caso aplicativo de diseño de sitios web, el resultado de un trabajo de grado correspondiente a la carrera de Licenciatura en Diseño Gráfico de la Facultad de Arte y Comunicación Audiovisual de la Escuela Superior Politécnica del Litoral. Expresamos un especial agradecimiento a la comunidad relacionada con el Trastorno del Espectro Autista la cual fue parte fundamental para el proceso de investigación sobre el que se basó este proyecto de titulación.

\section{REFERENCIAS}

[1] N. Grant, S. Rodger, and T. Hoffmann: "Evaluation of autismrelated health information on the Web," Journal of Applied Research in Intellectual Disabilities, 2015, 28, (4), pp. 276-282

[2] C. López-Chávez and M.-d.-L. Larrea-Castelo: "Autismo en Ecuador: Un grupo social en espera de atención," Revista Ecuatoriana de Neurología, 2017, 26, (3), pp. 203-214

[3] B. Reichow, J.I. Halpern, T.B. Steinhoff, N. Letsinger, A. Naples, and F.R. Volkmar: "Characteristics and quality of autism websites," 
Journal of autism and developmental disorders, 2012, 42, (6), pp. 1263-1274

[4] J. Artigas-Pallarés and I. Paula: "El autismo 70 años después de Leo Kanner y Hans Asperger," Revista de la Asociación Española de Neuropsiquiatría, 2012, 32, (115), pp. 567-587

[5] B.S. Salvadó, M.B. Palau, M.T. Clofent, M.C. Montero, and M.A.L. Hernández: "Modelos de intervención global en personas con trastorno del espectro autista," (C) Revista de Neurologia, 2012, vol. 54, núm. Supl 1, p. 63-71, 2012

[6] J.C. McPartland, B. Reichow, and F.R. Volkmar.: "Sensitivity and specificity of proposed DSM-5 diagnostic criteria for autism spectrum disorder," Journal of the American Academy of Child \& Adolescent Psychiatry, 2012, 51, (4), pp. 368-383

[7] M.d.S. Fortea Sevilla, M.O. Escandell Bermúdez, and J.J. Castro Sánchez: "Nuevas formas de abordaje del proceso diagnóstico del TEA después del DSM-5," International Journal of Developmental and Educational Psychology, 2014

[8] American-Psychiatric-Association: "Diagnostic and statistical manual of mental disorders (DSM-5®)" (American Psychiatric Pub, 2013. 2013)

[9] B.M. Prizant, A.M. Wetherby, and P.J. Rydell: "Communication intervention issues for children with autism spectrum disorders", 2000

[10] M.C. Pons Pons and J. Cardona Llorens: "Boletín ONUBIB: Enero 2015", 2015

[11] J. Chowdhury, J. Drummond, D. Fleming, and S. Neitfeld: "Content analysis of online autism specific sites", Journal on Developmental Disabilities, 2002, 9, (2), pp. 157-165

[12] G. Eysenbach and C. Köhler: "How do consumers search for and appraise health information on the world wide web? Qualitative study using focus groups, usability tests, and in-depth interviews", Bmj, 2002, 324, (7337), pp. 573-577

[13] P. Scullard, C. Peacock, and P. Davies: "Googling children's health reliability of medical advice on the internet", Archives of disease in childhood, 2010, 95, (8), pp. 580-582

[14] E.V. Bernstam, D.M. Shelton, M. Walji, and F. Meric-Bernstam: "Instruments to assess the quality of health information on the World Wide Web: what can our patients actually use?", International journal of medical informatics, 2005, 74, (1), pp. 1319

[15] R. Pedraza-Jiménez, S. Blanco, L. Codina, and V. Cavaller: "Diseño conceptual y especificación de requerimientos para el desarrollo y rediseño de sitios web", El profesional de la información, 2013, 22, (1), pp. 74-79

[16] A.E.A. Veloz: "De la interfaz del usuario al responsive web design", Revista AUC, 2016, (37), pp. 59-66

[17] A. Harrell: "Creative Direction in a Digital World: A Guide to Being a Modern Creative Director" (CRC Press, 2017. 2017)

[18] S. Krug: "Don't make me think!: a common sense approach to Web usability" (Pearson Education India, 2000. 2000)

[19] N.I. Solorzano, L. Sanzogni, and L. Houghton: "Effectiveness of using Pluralist Methodology in Information System Adoption Studies", in Editor (Ed.)^(Eds.): (IEEE, 2014, edn.), pp. 1-6

[20] Y.M. Hassan and F.J.F. Martín: "Propuesta de adaptación de la metología de diseño centrado en el usuario para el desarrollo de sitios web accesibles", 2013

[21] T. Brown: "Design thinking. harvard business review", Harvard Business Review, 2008

[22] J.P. DAuria: "Autism On the Web: Oh, the Places You'll Go!", Journal of Pediatric Health Care, 2010, 24, (6), pp. e11-e15

\section{ANEXO}

A. Cuestionario semiestructurado para entrevistas a padres de niños, niñas y jóvenes diagnosticados con Trastorno del Espectro Autista (TEA)

1. ¿Cómo llegó al profesional que evaluó y finalmente le dio el diagnóstico de TEA de su hijo/a?

2. Una vez recibido el diagnóstico, ¿por qué medios obtuvo usted información con respecto al TEA y las posibles opciones de tratamiento?

3. Dentro de su experiencia, ¿fue fácil encontrar herramientas para sobrellevar la etapa de duelo luego de recibir el diagnóstico de TEA de su hijo/a? Explique.

4. Como padre/familiar de una persona con autismo, ¿qué contenidos considera que serían de utilidad encontrar dentro de un sitio web como herramientas para el acompañamiento de su familiar?

5. ¿De qué manera obtiene usted el material de apoyo necesario para la guía terapéutica diaria de su hijo/a?

6. ¿Conoce usted cuáles son los beneficios a los que tiene derecho su familiar al tener una discapacidad? Menciónelos.

7. ¿Le parece que sería de gran ayuda poder compartir experiencias con otros padres $\mathrm{o}$ familiares? ¿Por qué? 